\title{
Surface Soil Effects Studies Based on H/V Ratios of Microtremors at Kingston Metropolitan Area, Jamaica
}

\author{
Walter Salazar ${ }^{1}$, Lyndon Brown ${ }^{2}$ and Garth Mannette ${ }^{1}$ \\ 1. Seismic Research Centre, The University of the West Indies (UWI), St. Augustine, Trinidad and Tobago \\ 2. Earthquake Unit, The University of the West Indies (UWI), Mona, Kingston, Jamaica
}

\begin{abstract}
The authors performed single mobile microtremor measurements at 218 sites at KMA (Kingston Metropolitan Area) with the objective of estimating the amplification effects due to the earthquake ground motion on the surface geology. The Fourier transform was applied to the most stationary parts of the triaxial wave motion recordings for each individual site and applied the traditional Nakamura technique, namely, the horizontal to vertical spectral ratio $(\mathrm{H} / \mathrm{V})$ to retrieve the predominant shear wave period of vibration of the soil profiles above the bedrock. The results yield predominant long periods of about 3.0-4.0 s in the port area and the waterfront, 1.0-2.0 s in the central part of Kingston, 0.3-1.0 s in Portmore and very stiff soil conditions in the surrounding area of the city. The results coincide fairly well with previous geological studies in the region, geotechnical data in boreholes, gravimetric measurements and strong motion recordings, suggesting a high degree of amplification of ground motion in the whole period range of engineering interest. Additionally, the authors obtained the liquefaction vulnerability factor $K_{g}$ proposed by Nakamura based on the H/V ratio of microtremors. The results suggest that the port area, the waterfront and the Port Royal are highly susceptible to liquefaction. Finally, the authors obtained fundamental periods of vibration based on microtremor measurements on the roof and the basement of four important buildings in the KMA and indicated future lines of research employing ambient noise measurements on structures.
\end{abstract}

Key words: Microtremors, Rayleigh and S-waves, amplification factor, fundamental period of vibration.

\section{Introduction}

Several researches documenting the destructiveness of several seismic events have established the pervasive influence of the sedimentary deposits on the preferential distribution of damages, such distribution appears to correlate well with the degree of amplifications caused by the surface geology, the authors can then regard the local distribution of the ground shaking intensity as a phenomenon closely related to the filtering effects of the soil profile $[1,2]$. Several studies have shown that Nakamura's technique [3] for estimating shear wave resonant periods is a robust method that can yield useful information regarding the soil profile of a site in the near surface. In this work, the authors study the site effects in KMA

Corresponding author: Walter Salazar, doctor of engineering, research fellow, research fields: earthquake engineering and engineering seismology. E-mail: walter.salazar@uwiseismic.com.
(Kingston Metropolitan Area) by performing single mobile microtremor measurements at 218 sites. In the first section, the authors introduce the surface geological setting of KMA based on available references for the city, secondly, an explanation of the methodology involved in the collection and processing of the microtremor data is presented and then outlined the theoretical background of the Nakamura technique to retrieve the quasi-transfer function of the soil profile. From this study, a new isoperiod contour map and a 3-D basin depth for the KMA have been proposed. The quasi transfer functions obtained by the microtremors are validated with available gravity, boreholes and strong motion data for the KMA. Finally, the authors assessed the liquefaction potential based on their microtremors recording, the water table level and the ground level shaking proposed by the new seismic hazard maps for Jamaica presented in the previous issues. 


\section{Geological Setting of Kingston Metropolitan Area}

The Liguanea Plain is a quaternary alluvial fan of the Hope River that drains the mountains to the northeast of Kingston forming the southern boundaries of the KMA. It consists of poorly sorted sands and gravels interspersed with layers of clay and sand. Occasionally, boulders of volcanic rock and conglomerate are also found [4]. The fan rises gently from sea level at Kingston harbour to more than $200 \mathrm{~m}$ elevation at Mona in the northeast, where it meets the Hope River at the base of the mountain range, the northern limits of the KMA used in this study. Few wells dug in the fan sediments have reached bedrock, hence the shape of the underlying basement and the thickness of the alluvium are not well known. To better constrain depth to basement rock, a gravity survey was conducted along two transects across the Liguanea Plain [5]. The results indicate a gradual deepening to 500-600 $\mathrm{m}$ at the Kingston waterfront with a more uniform depths of 300-400 m with undulations found along an east-west profile. The average shear-wave velocity of the fan sediments was estimated from well logs to be 320-495 $\mathrm{m} / \mathrm{s}$ and the basement rock was assumed to be Miocene Limestone. The surrounding hills to the northwest in Stony Hill and on the Limestone plateaus of Long Mountain all sit on Tertiary Limestone, these are areas of recent uplift and show high levels of fault escarpments, to the northeast are the highly jointed clastic sedimentary and volcanoclastic rocks of the Wagwater Formation showing recent slope failure deposits where currently new developments are continuously being built on the colluvial slope deposits of former landslippage.

The southern extension of the tombola that drains alluvial deposits along the Palisadoes now exists as one continuous landmass previously existing as individual cays that have progressively been joined with some amount of anthropogenic interference. The westward extension of the Palisadoes is located at the old buccaneering city of Port Royal. This once infamous city that was destroyed in the major earthquake M 7 [6] of 1692 is made up of discontinuous coral reefs connected by sands and gravels deposited by longshore drift from the estuaries of the Hope, Cane, Yallahs and Morant Rivers to the east of Kingston. The predominant deposits are loose sand deposits which are highly susceptible to liquefaction due to its shallow water table and poorly compacted deposits. The northwest limit of the KMA in the area of Stony Hill sits at an elevation of $1,400 \mathrm{ft}$. with the underlying rocks of the White Limestone plateau of the eastern extension of the Troy Formation.

Most of the waterfront sections of the city are built on engineered fill on which sits significant sections of the infrastructure of the city. There are also some sections of artificial fill or man-made ground which are non-engineered, which forms parts of downtown Kingston, Kingston harbour, the industrial zone leading to the airport, and also in the west area of the Newport where the activity is again modified by engineered fill, as shown in Fig. 1.

Most of the rocks in the surrounding mountain overlooking the plain are extensively faulted. The southern part of the Wagwater Trough and westernmost extension of the Plantain Garden fault system separates the Liguanea Plain from these outcrops. The northwest trending Wagwater Fault at the northern limits of the Liguanea Plain is associated with many micro-earthquakes [7].

On average over 200 earthquakes are recorded annually by the Jamaica Seismograph Network. These events have epicenters both locally (on-land and within the coastal waters) and regionally (outside of the local region but within $400 \mathrm{~km}$ from the Jamaica Seismograph Network). At least 10 of these earthquakes are described as felt events. Current earthquake frequency data from the earthquake unit at UWI (University of the West Indies) Mona show the highest levels of seismicity is associated with the eastern part of Jamaica (Kingston St. Andrew, Portland $\&$ St. Thomas) accounting for over $75 \%$ of the earthquake 


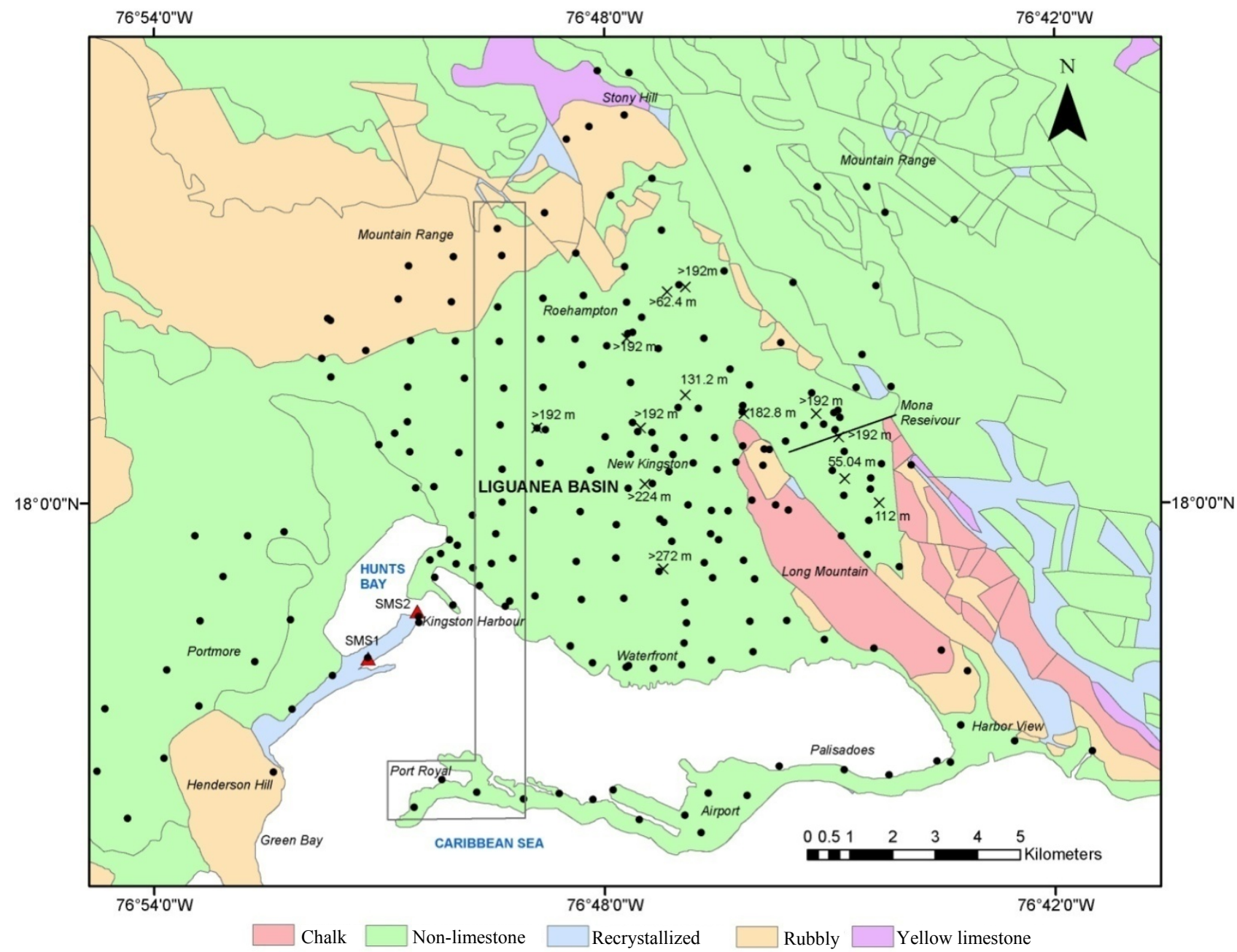

Fig. 1 General geological map of Kingston Metropolitan Area and microtremor points surveyed (black solid circles). The polygon includes the wave motion of microtrermors and the horizontal to vertical $\mathrm{H} / \mathrm{V}$ spectral ratios presented in Figs. 5 and 6. The crosses $(\mathrm{X})$ denote boreholes indicating the depth of the bedrock or the maximum depth reached ( $>$ ). The red triangles denote strong motion stations (SMS1 and SMS2).

events on the island. The new probabilistic seismic hazard maps developed for Jamaica at rock site conditions presented in previous issues confirm that KMA is subjected to a moderate/high seismicity based on a peak ground acceleration of $0.24 \mathrm{~g}$ for 475 years return period and spectral accelerations for periods of $0.2 \mathrm{~s}$ and $1.0 \mathrm{~s}$ yielding levels of $1.05 \mathrm{~g}$ and $0.16 \mathrm{~g}$ respectively for 2,475 years return period.

\section{Theoretical Background of $H / V$ Ratios of Microtremors}

Microtremors are a general term for constantly existing minute vibrations at the surface of the ground with body and surface waves being the main component of microtremors. Microtremors show specific characteristics of the surface geology, and are periodic and contain the amplification characteristics of the soil, which is often referred to as site-effect. The periodic characteristics of microtremors are similar to the ones during earthquakes, however, the amplitude of microtremors is quite small caused by human activity, machinery, traffic, etc.. Due to the close relation between the nature of microtremors and the fundamental dynamic behavior of the surface soil layers, these small vibrations are useful and also well known in the field of earthquake engineering. To assess 
the transfer functions, the authors used the traditional method of Nakamura, the horizontal to vertical spectral $(\mathrm{H} / \mathrm{V})$ ratio.

While studying the characteristics of microtremors, Nogoshi and Igarashi [8] found a conspicuous similitude of the horizontal to vertical spectral ratios $(\mathrm{H} / \mathrm{V})$ of microtremors to that of Rayleigh waves. This led them in the first instance to suggest Rayleigh waves as the main component of microtremor recordings. This constitutes the origin of the horizontal to vertical spectral ratio technique applied in the estimation of the amplification of the horizontal motion in the presence of surface layers using microtremors $[9,10]$. Nakamura [3] revisited this method and brought it back to the engineering community as non-reference site technique providing a theoretical interpretation in the form of his semi-quasi transfer spectrum model incorporating the effects of Rayleigh and S-waves in his formulation. Nakamura's formulation of the $\mathrm{H} / \mathrm{V}$ spectral ratio departs from the assumption that the vertical component of motion reaches the surface without undergoing significant amplification within the frequency range of interest in engineering, thereby retaining the characteristics of the horizontal motion at the engineering bedrock. Nakamura [3] proved the validity of this crucial assumption at the Tabata and Kanonomiya sites in Japan for the usual frequency range of practical interest in engineering, namely, from 0.125 Hertz to 10 Hertz $(0.1 \mathrm{~s}$ to $8.0 \mathrm{~s})$. The authors define $H_{i}(f)$ and $H_{b}(f)$ as the surface and engineering bedrock horizontal Fourier amplitude spectrum of microtremors, respectively. If $f$ denotes the frequency of ground motion, then the authors can express the site effects function $G_{i}(f)$ at a site $i$, by applying the following expression:

$$
G_{i}(f)=H_{i}(f) / H_{b}(f)
$$

It seems worth noting that although dealing with microtremor recordings, Eq. (1) results in a transfer function formulation quite similar to that proposed by Borchedt [11] for earthquake ground motion recordings. In their original formulation, Nakamura [3] assumed that the energy of microtremors comprises both body and surface waves, and that the surface sources generate Rayleigh waves equally affecting the horizontal and vertical components of motion [9]. If the authors assume that the vertical motion due only to body waves undergoes no amplification, then the authors can express the effect of the Rayleigh waves on the vertical motion $E_{S(f)}$ as follows:

$$
E_{S}(f)=V_{i}(f) / V_{b}(f)
$$

According to this development, $E_{S}$ yields 1.0 in the absence of Rayleigh waves, whereas values over 1.0 indicate the effect of Rayleigh waves. The next step in this formulation comprises the vertical and horizontal components of motion assuming a similar effect of Rayleigh waves on both. On these premises, the formulation of the horizontal to vertical motion spectral ratio $(H / V)$ aims at eliminating the Rayleigh wave's effect via calculation of the ratio $G_{i}(f) / E_{S}(f)$ :

$$
H / V=\frac{G_{i}(f)}{E_{S}(f)}=\frac{H_{i(f)} / H_{b}(f)}{V_{i}(f) / V_{b}(f)}=\frac{H_{i}(f)}{V_{i}(f)} * \frac{V_{b}(f)}{H_{b}(f)} \text { (3) }
$$

According to the previous assumptions, at the engineering bedrock, the ratio $H_{b}(f) / V_{b}(f)$ equates 1.0 within a relatively wide period range. Accordingly, the authors can estimate the soil transfer function by taking the $H_{i}(f) / V_{i}(f)$ ratios of the surface recordings.

\section{Microtremors Survey and Data Processing}

The authors performed microtremors survey at Kingston Metropolitan Area (Fig. 1) in November 2011, June 2012 and November 2012. A total of 218 measurements with an average of $500 \mathrm{~m}-1 \mathrm{~km}$ spacing was made employing a triaxial Tokyo Sokushin 24 bit sensor, model CV-374A with a flat response between $0.1 \mathrm{~Hz}$ to $10 \mathrm{~Hz}$ (Fig. 2) and a recording system of 100 samples per second, the sensors measured micromotion in terms of acceleration.

The following six steps were adopted to perform the surveys and to analyse the data (Fig. 3):

(1) The authors tried to make the measurement whenever in a silent environment for at least $5 \mathrm{~min}$ 


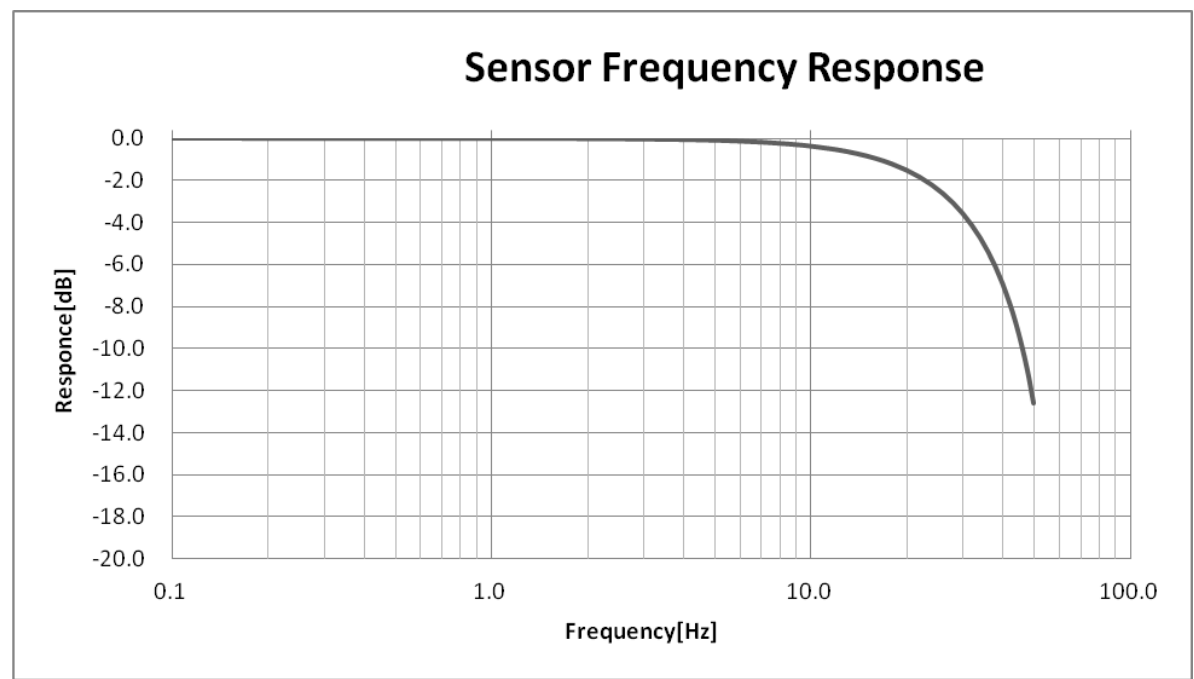

Fig. 2 Transfer function for the Tokyo Sokushin Sensor CV374-A (Courtesy of Isamu Yokoi).

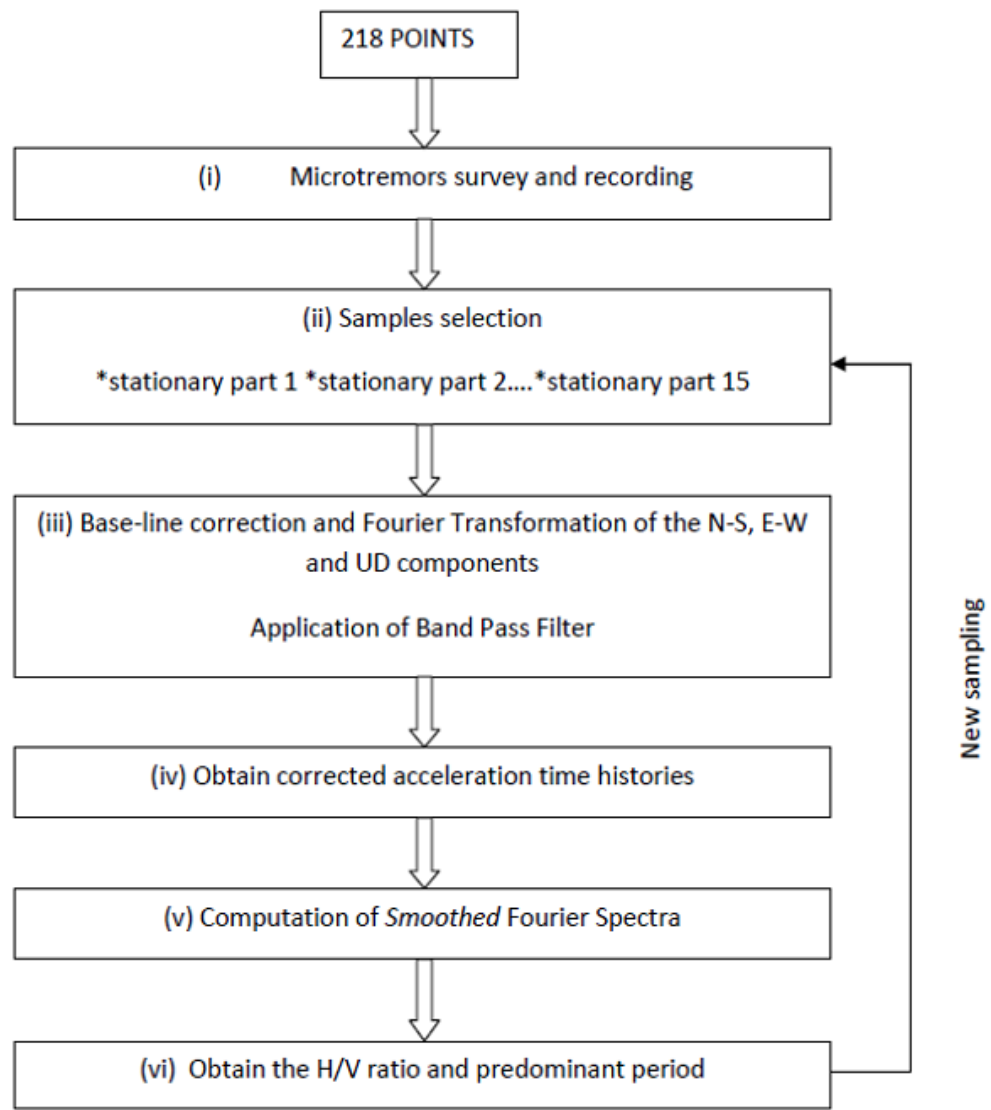

Fig. 3 Flowchart showing the methodology for data collection and digital signal processing.

at each location (trying to maintain the survey, interval, however there are some locations where the authors had to collect in the closest possible location relative to this interval), since the instrument can easily record surrounding noise such as heavy traffic. These are reflected in spikes on the records that can perturb the periodic features of the microtremors. The horizontal sensors were located with north-south and east-west orientations (magnetic north);

(2) Samples of $20 \mathrm{~s}$ of the stationary parts of the 
recording were selected initially for processing;

(3) For each sample, the authors applied a baseline correction that targets the elimination of the noise associated with the unknown zero-level line associated with long period components, this serves to remove the signal offset responsible for constant shifts of all acceleration values. The Fourier transform was then applied to the records and with the band pass raised cosine filter. The authors selected the low and high cutoff frequencies in the filter according to the dynamic amplification factor (flat response) provided by the sensor manufacturer (Fig. 2);

(4) The authors applied the inverse Fourier transform to obtain the corrected acceleration time history for each record;

(5) For each selected stationary part, the authors
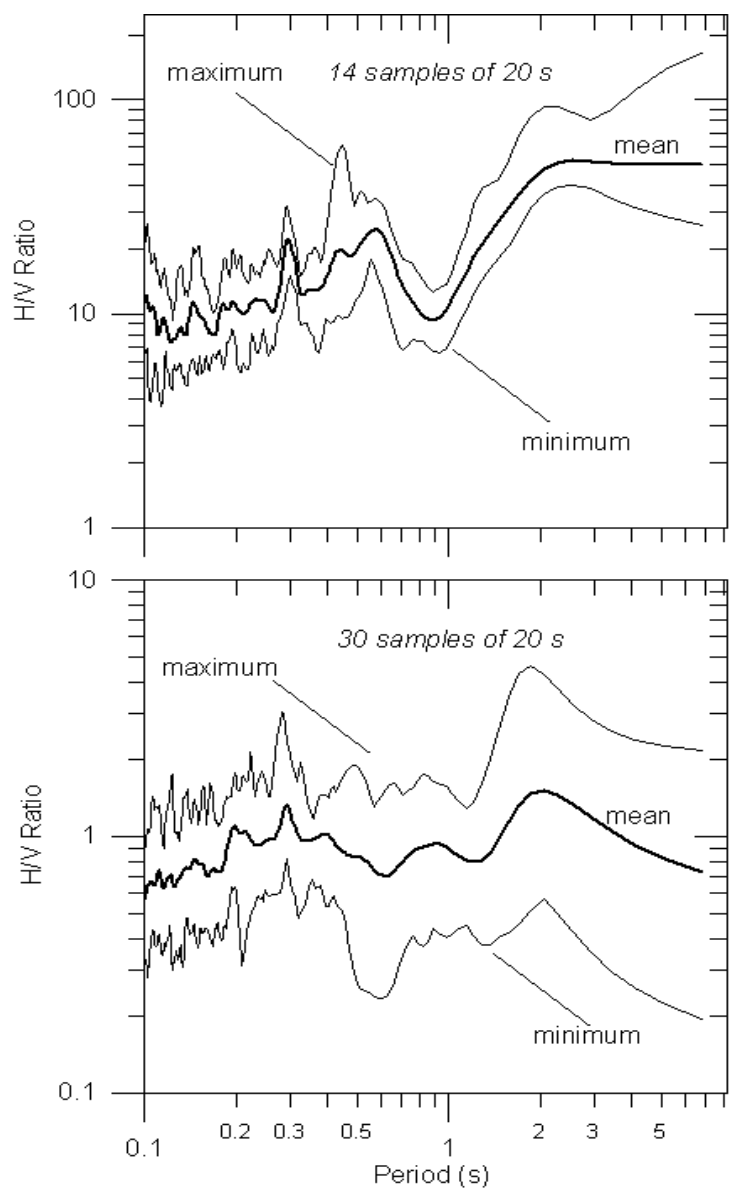

computed the resultant Fourier acceleration amplitude spectrum and the correspondent uncertainties for the horizontal and vertical components of motion. The authors smoothed the spectra applying a Parzen Window with a bandwidth of $0.4 \mathrm{~Hz}$;

(6) Finally, the authors calculated the horizontal to vertical spectral ratio $(\mathrm{H} / \mathrm{V})$ employing the resultant vector of the orthogonal north-south and east-west components of motion and averaging the results for all the stationary parts selected for each record, the maximum and minimum ratios were computed as well. The authors identified the peak in the $\mathrm{H} / \mathrm{V}$ ratio and located it in the geographical information system. They plotted the spectra for $0.1 \mathrm{~s}$ to $8.0 \mathrm{~s}$ coinciding with the period range of interest for earthquake engineering practice.
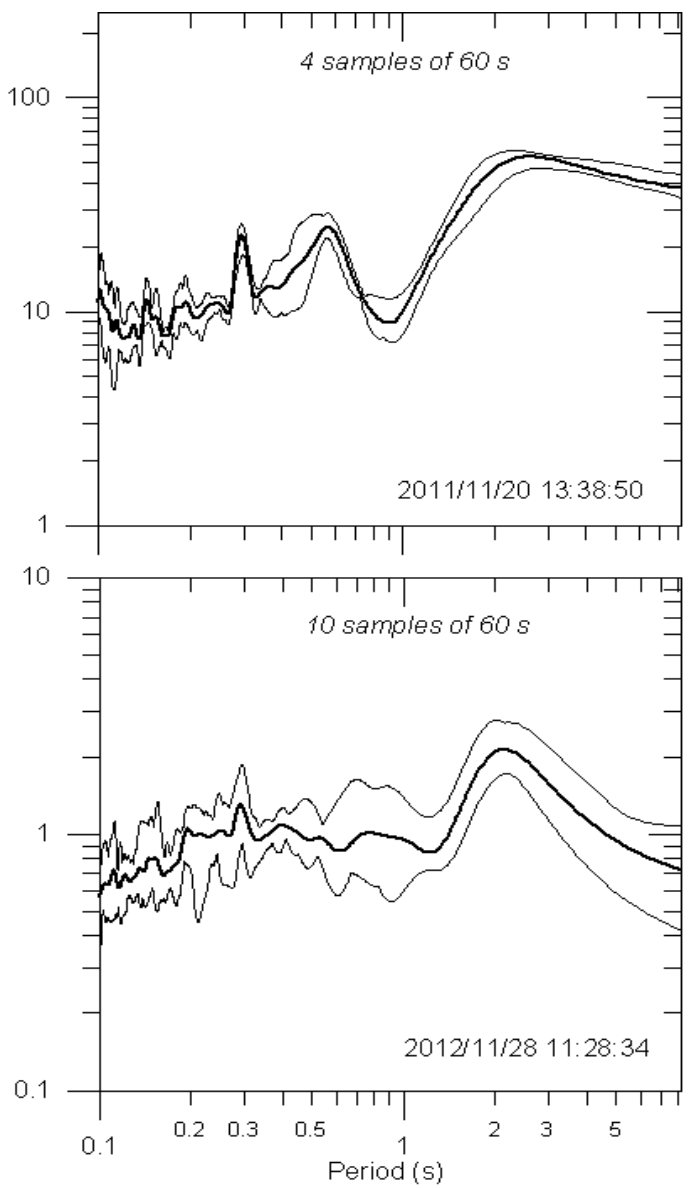

Fig. 4 Horizontal to vertical spectral ratio $(\mathrm{H} / \mathrm{V})$ for different lengths of sampling data: microtremor measurement recorded at 2011/11/20 13:38:50 with coordinates $17^{\circ} 59.301 ' \mathrm{~N}, \mathbf{7 6}^{\circ} 47.855^{\prime} \mathrm{W}$ (Top); microtremor measurement recorded at 2011/11/28 11:28:34 with coordinates $17^{\circ} 59.6082^{\prime} \mathrm{N}, 7^{\circ} 46.5924^{\prime} \mathrm{W}$ (Bottom). The maximum, minimum and the mean of the $\mathrm{H} / \mathrm{V}$ ratios are presented for each recording. 
It should be noted that an iterative procedure is sometimes necessary to improve the resolution and to reduce the uncertainties in the results especially when long period ground motion is predominant in the spectrum (Fig. 4). Stationary samples of $20 \mathrm{~s}$ sometimes are not enough for the resolution of the spectrum above periods of $1.0 \mathrm{~s}$ : in this case, the authors increased the duration of the samples to $60 \mathrm{~s}$ and repeated the procedure for (ii) to (vi) in Fig. 3. In other cases, the authors repeated the measurements recording for $15 \mathrm{~min}$ in those locations where long period ground motions appeared and increased the time of the samples and also employing $60 \mathrm{~s}$ to make the signal processing scheme.

\subsection{Analysis and Interpretation}

The authors present in Fig. 5 the horizontal wave motion of microtremors for the transverse section from north to south depicted in Fig. 1. It is clear that the characteristic of microtremors varies considerably along KMA in terms of amplitude and period of motion. Generally, the amplitude and the period increase from the mountain region in the north toward the south at the shore in the port area, the amplitude varies from 0.1 $\mathrm{cm} / \mathrm{s}^{2}$ to $2.0 \mathrm{~cm} / \mathrm{s}^{2}$ and the period from $0.1 \mathrm{~s}$ to $3-4 \mathrm{~s}$. The authors present the plots of the H/V ratios for the same points in Fig. 6 and plot the predominant periods for the whole city in Fig. 7. From east-west, there is a minor change in the periods of the unit.

Along the Liguanea Basin and at the eastern part of the waterfront, the authors observe an average period $T$ of $2.0 \mathrm{~s}$ confirming the presence of the thick alluvial deposits on KMA basin (Fig. 7). The average shear wave velocity $\left(V_{S}\right)$ of the fan sediments is estimated from well $\operatorname{logs}$ to be $320-495 \mathrm{~m} / \mathrm{s}(410 \mathrm{~m} / \mathrm{s})$ [5]. Taking the fundamental period $T$ in seconds of a soil profile equal to:

$$
T(s)=\frac{4 H}{V_{S}}
$$

Inverting Eq. (4) for $H$ yields an average depth of $\approx$ $200 \mathrm{~m}$ in the Liguanea Plain above the Miocene Limestone (see depth of the boreholes in Fig. 1), which is considered here as the engineering bedrock. The microtremor results primarily coincide with the general geology setting of the basin where poorly consolidated alluvial deposits with the deepest boreholes down to depth at least $200 \mathrm{~m}$, Aspinall and Shepherd [12] suggest layers of sand retained in the shallower parts with clays comprising deposits of the deeper parts.

The shear wave velocity $V_{R}$ for the limestone is equal to:

$$
V_{R}=\sqrt{\frac{\mu}{\rho}}
$$

where, $\mu$ is the rigidity modulus and $\rho$ is the density. Taking typical values for the limestone of $\mu=24 \mathrm{GPa}$, $\rho=2.7 \mathrm{~g} / \mathrm{cm}^{3}$ yields a $V_{R}=943 \mathrm{~m} / \mathrm{s}$. Employing an optional Eq. (6) to find the depth of the bedrock $H$ employing microtremors is as follows [13]:

$$
H=\frac{V_{R}}{4 A_{S} F_{g}}
$$

where, $A_{S}$ is the ratio $V_{R} / V_{S}$ and $F_{g}$ is the predominant frequency based on microtremors. Setting $V_{R}=943$ $\mathrm{m} / \mathrm{s}$ for the limestone and taking $A_{S}=943 / 410=2.30$ and $F_{g}$ as $0.50 \mathrm{~Hz}\left(T_{2}=2.0 \mathrm{~s}\right)$ yields a depth $H=205 \mathrm{~m}$. Note that Eq. (6) is equivalent to Eq. (4), however, the computed $A_{S}$ ratio determines the contrast between the rock and the soil that is related to the sharp peak and the through observed in the $\mathrm{H} / \mathrm{V}$ ratios (Fig. 6c).

The longest periods of about $3.0 \mathrm{~s}$ to $4.0 \mathrm{~s}$ are observed in the port area to the west of KMA and the sand spit that connects Portmore and KMA, presumably reclaimed land areas with the water table is commonly close to the surface. The results coincide with a soil profile depth of about 310-410 $\mathrm{m}$ as a result of natural sedimentation and landfill. Also, Aspinall and Shepherd [12] suggest that the deepest part may exceed $300 \mathrm{~m}$ in this area. The general trend of the increasing depth of the sediments from north to south in KMA is also confirmed by the gravimetric survey performed by the National Disaster Research [5] yielding thickness of the alluvial deposits ranging from $100 \mathrm{~m}$ to $600 \mathrm{~m}$.

The authors found along the Palisadoes spit different periods of vibrations of the soil profiles, at the western part in Port Royal area the periods yield $1.0-2.0 \mathrm{~s}$ 


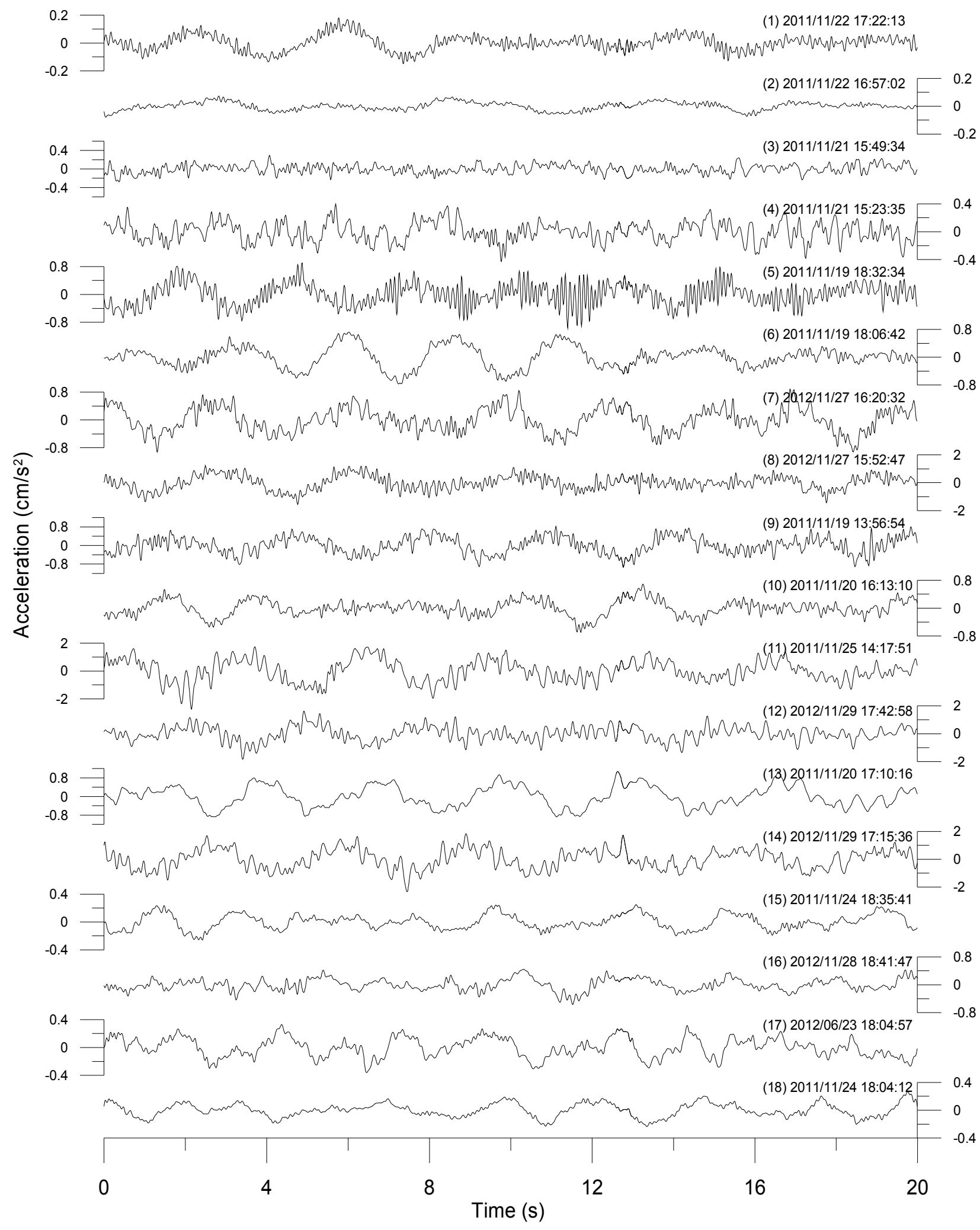

Fig. 5 Wave motion microtremors for the N-S component inside the polygon shown in Fig. 1. 
suggesting a loose intermediate soil depth profile of about 100-200 m. The shortest periods in the range of 0.3-0.6 $\mathrm{s}$ were found at the Norman Manley International Airport possibly due to compaction works related to the construction of the airport, however, soft soil conditions were found at the western edge of the runway with a period of $1.5 \mathrm{~s}$, suggesting a different degree of soil compaction during the construction process of the airport. At the eastern edge of the spit in the Harbour View, the authors found again period of $1.5 \mathrm{~s}$ related with the sediments deposited by the Hope River.

The spectral shape of the $\mathrm{H} / \mathrm{V}$ ratios and the absolute acceleration Fourier spectra introduce an insight of the wave propagation of microtremors (Fig. 8): the sediments above bedrock behave as a high-pass filter allowing the Rayleigh waves to propagate in the surface layers, however, the Rayleigh waves can not

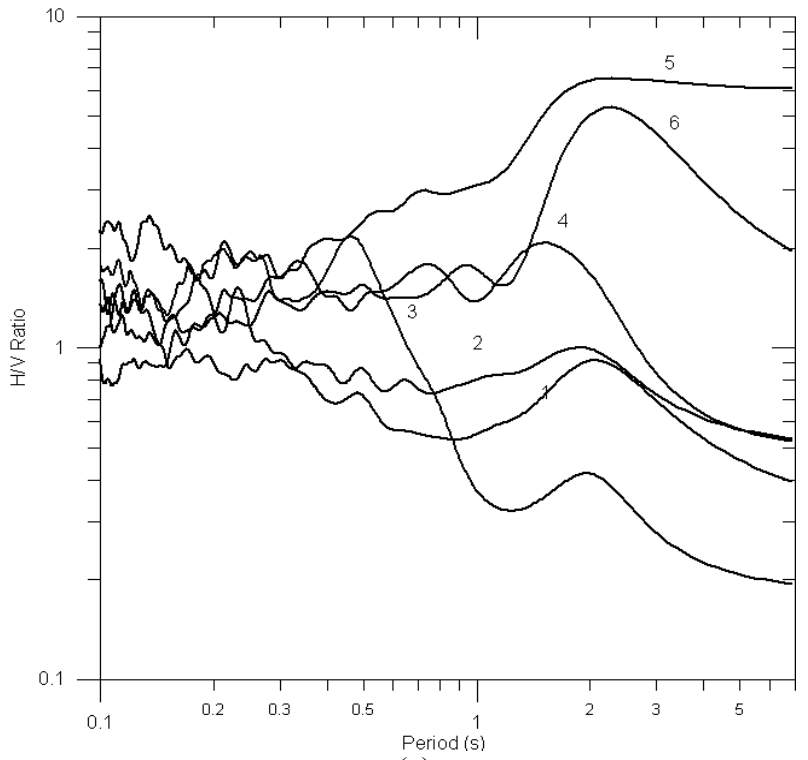

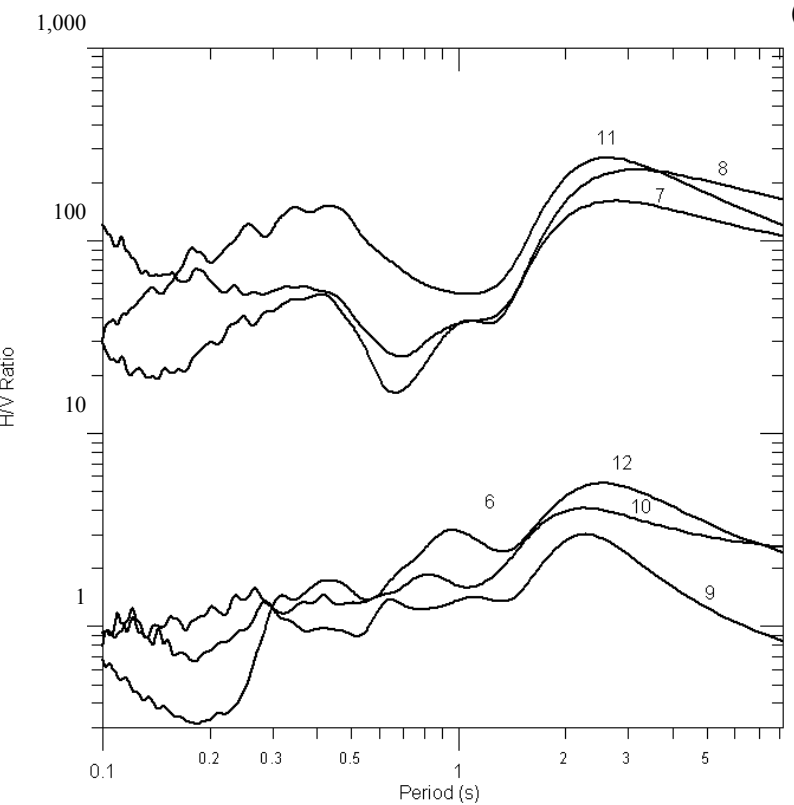

(b)

(a)

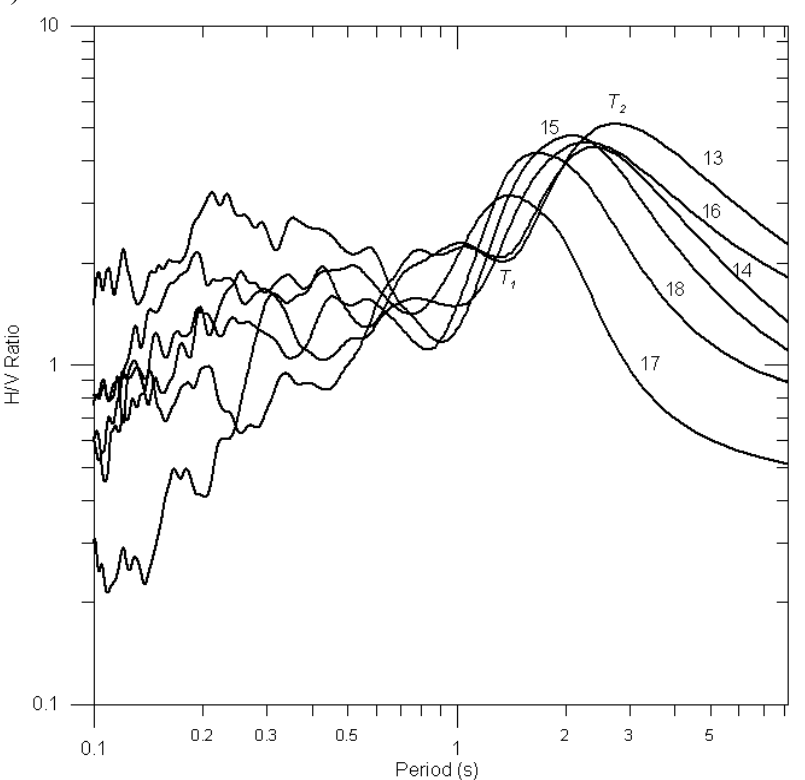

(c)

Fig. 6 Horizontal to vertical spectral ratio $(H / V)$ for the points inside the polygon depicted in Fig. 1, the numbers next to the ratios correspond to the same numbers depicted in Fig. 5, the authors computed the geometrical mean for the horizontal component of motion, $T_{1}$ is nearly $1 / 2 T_{2}$ indicating a high contrast between the sediments and the basement rock in KMA. 
propagate in the period range of the predominant period of the surface layers $T_{2}$ but can transmit the energy peak around the period of minimum group velocity ( $1 / 2$ of $T_{2}$ corresponding to the trough period $T_{1}$ in Figs. 8b-8d) which constitutes an Airy Phase. Note that through period $T_{1}$ is nearly half of the peak period $T_{2}$ in the H/V spectral ratios presented in Figs. 6 and 8. As a conclusion, the effect of multiple reflections of the $S$-waves is composed mainly around the predominant period $T_{2}$ and the period of maximum energy transmission of the Rayleigh waves is about a half $T_{2} \approx$ $T_{1}$ [14].

The sharp peak $\left(T_{2}\right)$ and a sharp trough $\left(T_{1}\right)$ suggests a high velocity contrast between the basement rock $\left(V_{R}\right)$ and the velocity of the surface layers $\left(V_{S}\right)$ yielding $V_{R} / V_{S} \geq 2.5$ [10]. It is noted that the $V_{R} / V_{S}$ ratio yields 2.3 between the limestone and the alluvium. Anomalous $\mathrm{H} / \mathrm{V}$ ratios above 100 are observed at some sites (Fig. 7), the authors explain this phenomenon in Section 5.

A further examination of the $\mathrm{H} / \mathrm{V}$ ratio for the harbour area (port) is presented in Fig. 9. The H/V ratio reflects three peaks at $3.0 \mathrm{~s}, 1.0 \mathrm{~s}$ and $0.4 \mathrm{~s}$, which presumably constitutes the fundamental mode and the harmonics of the soil profile in the port. An important characteristic of this quasi transfer function is that the peak observed in the second period of vibration is clearly caused by the trough in the vertical component physically representing the change from retrograde

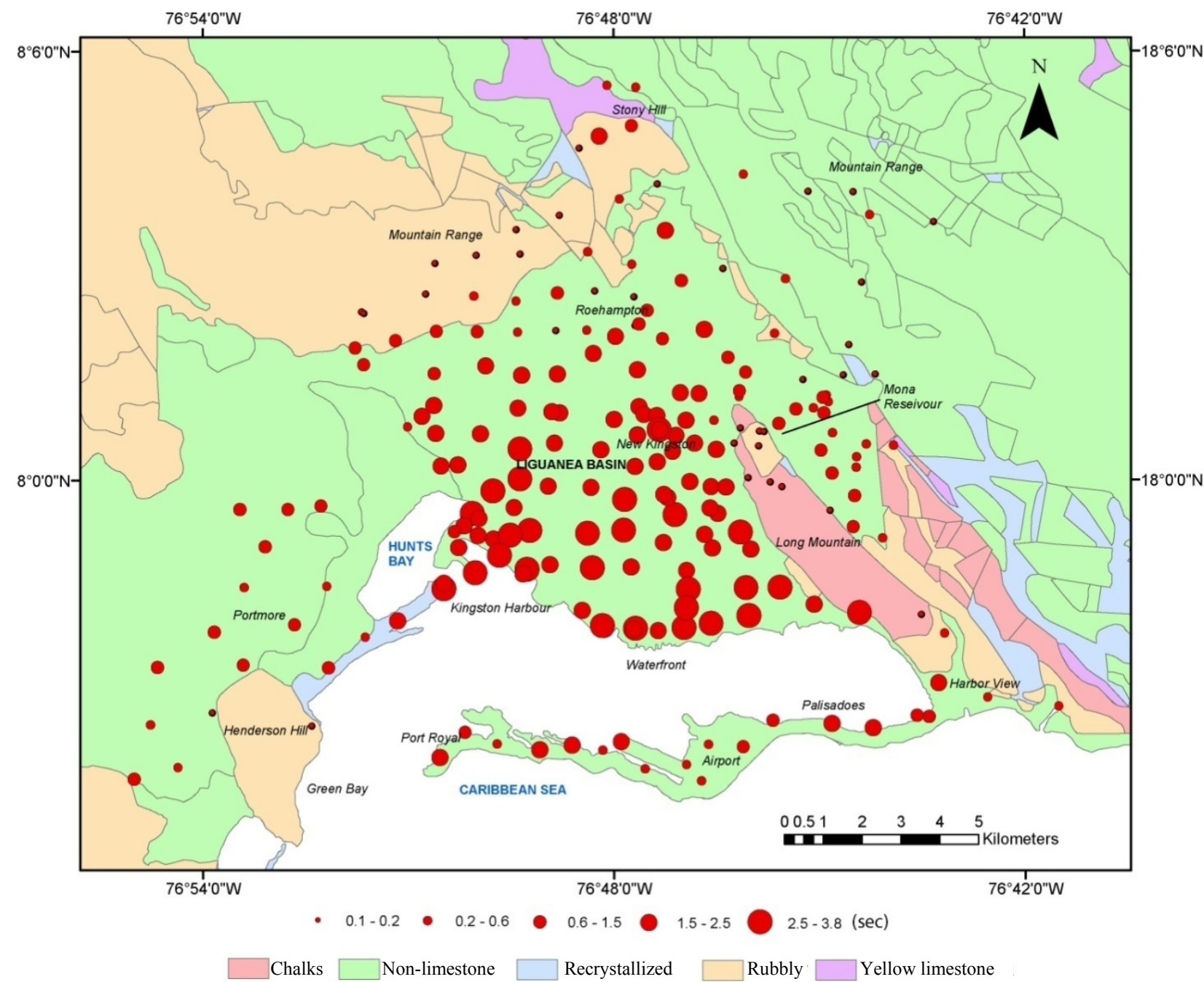

Fig. 7 Predominant period of soil based on horizontal to vertical spectral ratio $(\mathrm{H} / \mathrm{V})$ for the 218 points in Kingston Metropolitan Area. 

at Kingston Metropolitan Area, Jamaica
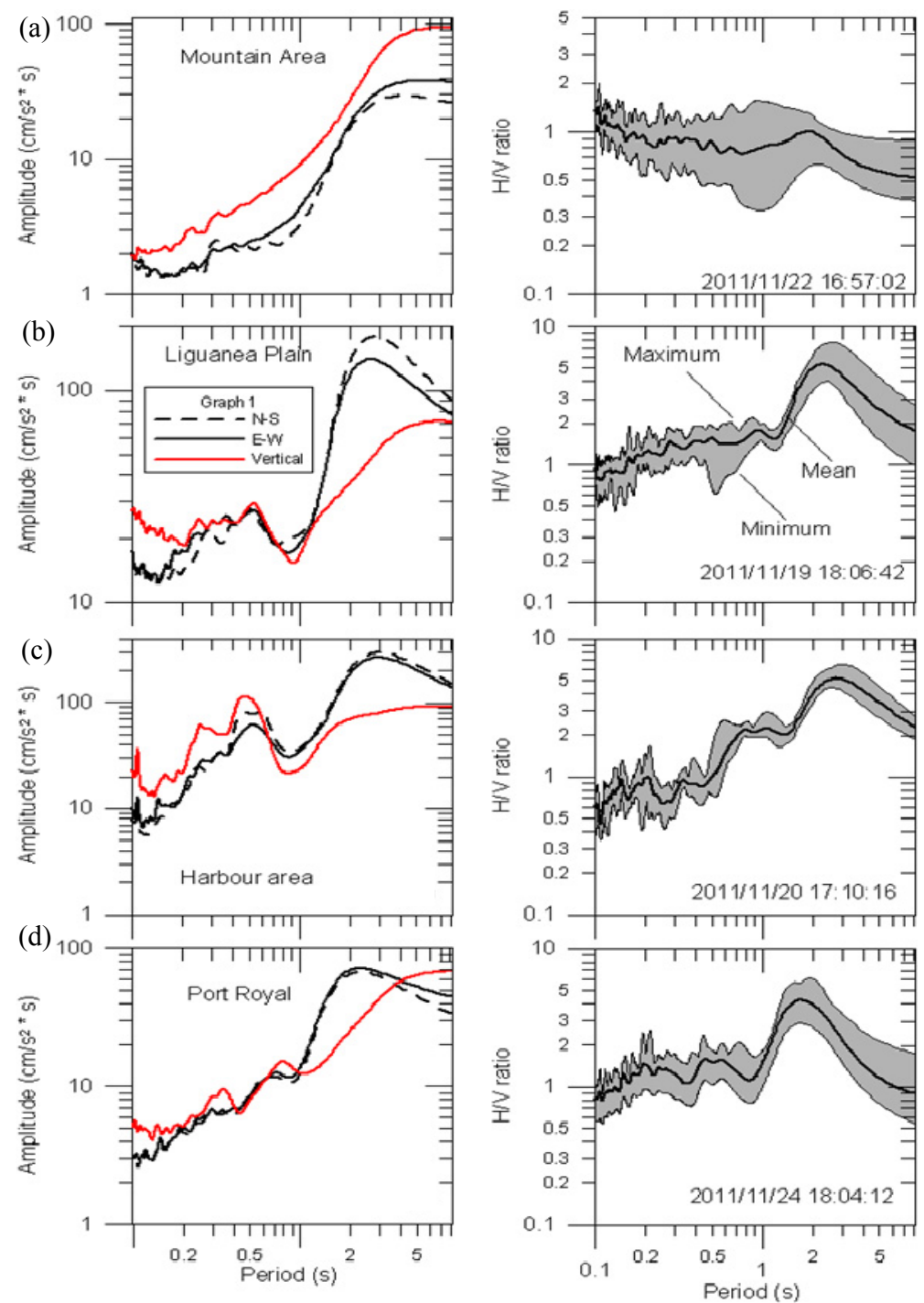

Fig. 8 Rock site (a) and sediments sites (b-d) characterized by the effect of multiple reflections of the S-waves around the predominant period. Left: Fourier amplitude spectra for the horizontal and vertical components of microtremors. Right: $\mathrm{H} / \mathrm{V}$ ratios, the horizontal motion is taken as the geometric mean of the N-S and $\mathrm{E}-\mathrm{W}$ components.

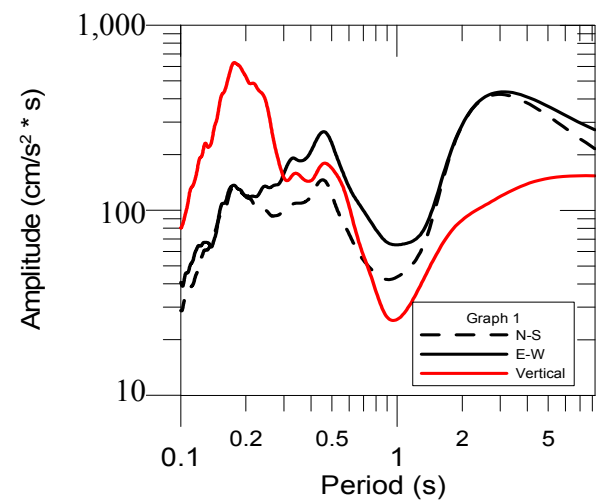

(a)

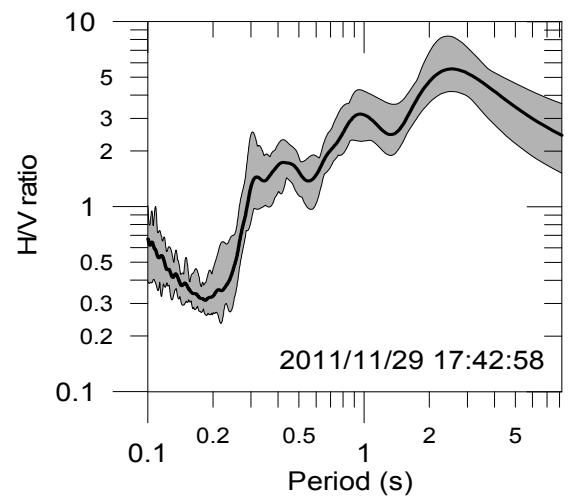

(b)

Fig. 9 A further examination of the $\mathrm{H} / \mathrm{V}$ ratio for the harbour area (port): (a): Fourier amplitude spectra for the horizontal and vertical components of microtremors; (b) $\mathrm{H} / \mathrm{V}$ ratios, the horizontal motion is taken as the geometric mean of the $\mathrm{N}-\mathrm{S}$ and $\mathrm{E}-\mathrm{W}$ components. The site is located in the harbor area with $\mathrm{H} / \mathrm{V}$ ratios showing the fundamental mode and the harmonics. 

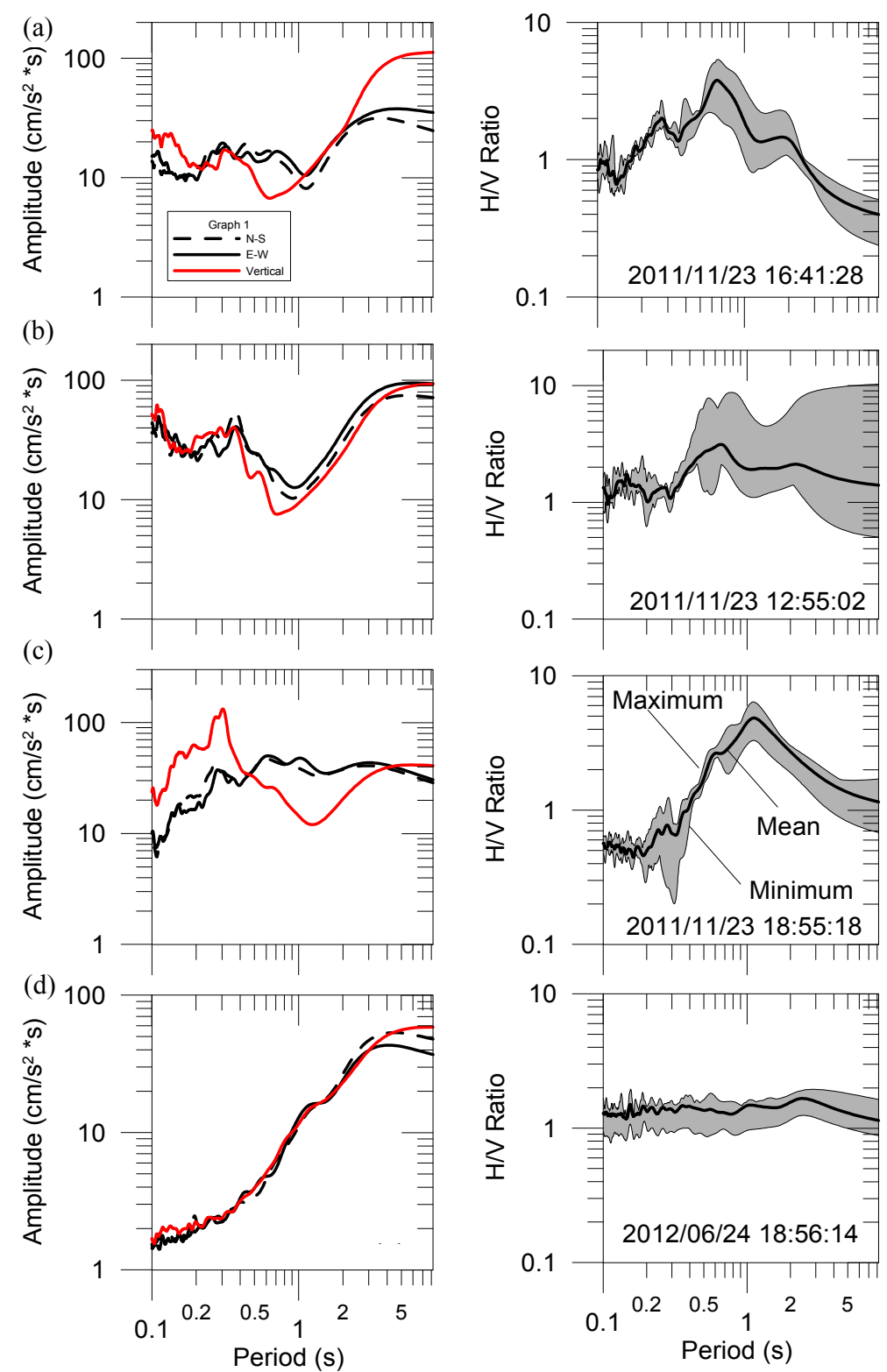

Fig. 10 Fourier amplitude spectra for the horizontal and vertical components of microtremors at Portmore area (Left); H/V ratios, the horizontal motion is taken as the geometric mean of the N-S and E-W components (Right).

to prograde particle motion at the surface, in other words, the ellipticity of the fundamental modes of Rayleigh waves explain such peak at the second mode of vibration, but is clearly not related with the resonant $\mathrm{S}$-wave fundamental period in the soil profile. This feature is also observed within the municipality of Portmore (Figs. 10a-10c) with the peaks in the period range of $0.3 \mathrm{~s}$ to $1.0 \mathrm{~s}$ caused by the trough in the vertical component, however, the shapes of the absolute spectra and the $\mathrm{H} / \mathrm{V}$ ratios yield different features for the wave propagation in comparison with the Liguanea Plain, the harbour area and Port Royal. It is noticed that the Portmore area was part of the flood-plain of the slow-moving Rio Cobre with the result of a deposition of great thickness of fine grained materials and with intercalations of sand deposits [15]. As a consequence of such intercalation of materials, the authors can suggest that the peak observed might correspond to the second mode of vibration constituting the predominant period in this case [16]. 
A flat $\mathrm{H} / \mathrm{V}$ ratio of 1.0 is observed at the foot of the limestone Port Henderson Hills near the Green Bay (Fig. 10d) and ratio of 1.0 is observed in the shore of the city for all frequencies of motion. A period of $1.0 \mathrm{~s}$ is observed in the shore of the city.

Stiff soils or rock site conditions are generally found on the hills surrounding KMA in the limestone hilly areas, yielding an $\mathrm{H} / \mathrm{V}$ ratio $\approx 1.0$ for periods between $0.1 \mathrm{~s}$ and $2.0 \mathrm{~s}$ (Fig. 8a), however, the authors observed soil sediments at some places in Stony Hill at the northern of KMA yielding fundamental periods of $1.2 \mathrm{~s}$. The authors also found visible outcrop-rock conditions toward to the north of KMA at the district of Roehampton and surrounding areas (i.e., Constant Springs and Arlene Gardens); these geological conditions were confirmed with the microtremor recordings.

At the north and east of Mona Reservoir, the authors found the most irregular pattern for the period of vibration between $0.6 \mathrm{~s}$ and $1.0 \mathrm{~s}$, there is no clear indication of a regular soil structure in this area, an intercalation of coarse gravels and sands are reported for this region [5].

The authors developed an isoperiod map for KMA employing the 218 microtremors points (Fig. 7) and interpolating the period values to a grid of $15 \mathrm{~m} \times 15 \mathrm{~m}$ via application of the minimum curvature method (Fig. 11). This map shows similar patterns for the work of Wald and Allen [17], yielding average shear wave velocities in the first $30 \mathrm{~m}$ based on topographic slopes at KMA. In a similar way, the authors developed a 3-D model sediment depth for KMA derived by inverting the depth $H$ of Eq. (4) setting an average shear wave velocity of $410 \mathrm{~m} / \mathrm{s}$ and using the predominant periods obtained by each H/V ratio of microtremors (Fig. 12). The thickness distribution in the city appears to correlate well with the MM (modified Mercalli) intensity distribution observed for the earthquake of January 13, 1993, M 5.5 and with shallow depth of 15 $\mathrm{km}$ located in the Blue Mountains [6].

Despite the epicenter was located to the north-east at a distance of about $15 \mathrm{~km}$ from central Kingston, high intensities of VIII MM were reported in the waterfront where the thickest sediments are located according to our model. Another earthquakes located $200 \mathrm{~km}$ away from KMA in the Oriente Fault Zone at the South Cuba has triggered intensities of IV MM in the Liguanea Plain.

\subsection{Comparison of Earthquake Motion Data and} Microtremors

The authors tried to elucidate the level of amplification in the KMA employing earthquake data and comparing them with microtremors, employing the $\mathrm{H} / \mathrm{V}$ ratio and an amplification factor developed by dividing the actual ground motion by the motion estimated at rock conditions using the $\omega^{2}$ model.

Brune [18] proposed a simple model to explain the earthquake source in the frequency domain. $\mathrm{He}$ considered a simple circular fault of radius $r$ that ruptures over its whole area at the same time [19]. The method relates the spectrum of the shear radiation to the stress released across the fault surface. The high frequency level of the source spectrum is controlled by the stress parameter (stress drop) and the low frequency level proportional to the seismic moment, then the observed spectra in this model depend on the moment magnitude and the stress drop [20]. The salient characteristics of the displacement spectrum in the low frequency level are given by Haskell [21]:

$$
\Omega_{o}=\frac{M_{o}}{4 \pi \rho R v_{s}^{3}} R_{\theta \phi}
$$

where, $M_{o}$ is the seismic moment in dyne-cm, $R_{\theta \phi}$ is the radiation pattern coefficient $(0.55$ for average radiation pattern of the double-couple radiation), $\rho$ is the density, $v_{S}$ is the crust shear wave velocity $(\mathrm{km} / \mathrm{s})$ and $R$ is the hypocentral distance. At higher frequencies longer than the corner frequency $f_{c}$ in the spectrum amplitudes falls as $f^{2}$ or $\omega^{2}$, where, $\omega$ (omega) denotes the circular frequency $(\omega=2 \pi f)$. The corner frequency can be found by: 


$$
f_{c}=4.9 \times 10^{6} v_{S}\left(\frac{\Delta \sigma}{M_{o}}\right)^{1 / 3}
$$

where, $\Delta \sigma$ is the stress drop in bars. Then displacement spectrum at a distance $R$ is:

$$
D(f)=\frac{M_{o}}{4 \pi \rho R v_{s}^{3}} R_{\theta \phi} *\left[\frac{1}{1+\left(f / f_{c}\right)^{2}}\right]
$$

McGuire and Hanks [22] suggested incorporating the quality factor $Q_{S}(f)$, to account the free-surface effect (using a factor of $F=2$ ) and the vectorial partitioning of energy into two components of equal amplitude (factor of $V=0.71$ ). Also, they suggested that the Fourier amplitude spectrum of acceleration can be obtained by multiplying the displacement spectrum by $(2 \pi f)^{2}$. Then, in a compact form, the Brune $\omega^{2}$ model acceleration spectrum near the source for horizontal component is Ref. [23]:

$$
A c(f)=(2 \pi f)^{2}\left[C M_{o} \frac{1}{1+\left(f / f_{c}\right)^{2}}\right] \frac{e^{-\pi f R / Q_{S}(f) v_{S}}}{R} * F
$$

where,

$$
C=\frac{R_{\theta \phi} V}{4 \pi \rho v_{s}^{3}}
$$

The stress drop and the seismic moment are used to define the source spectrum, which is obtained in Eq. (10) using the expression inside the brackets multiplied by $(2 \pi f)^{2}$ or prescribing $R=1.0$. The authors should remember that this constitutes an "apparent source spectra" since it refers to the fact that these representations are what the authors deduce from far-field observations [24].

To obtain the seismic moment $M_{o}$ (dyne-cm), we use the moment magnitude $M_{W}$ and using the formula [25] as follows:

$$
M_{W}=\frac{2}{3} \log M_{o}-10.7
$$

The authors calculated the amplification factors from the earthquake strong motion recordings dividing the observed Fourier amplitude spectra by the corresponding theoretical spectra employing Eq. (10) setting 100 bars of stress drop, the $Q_{S(f)}$ from

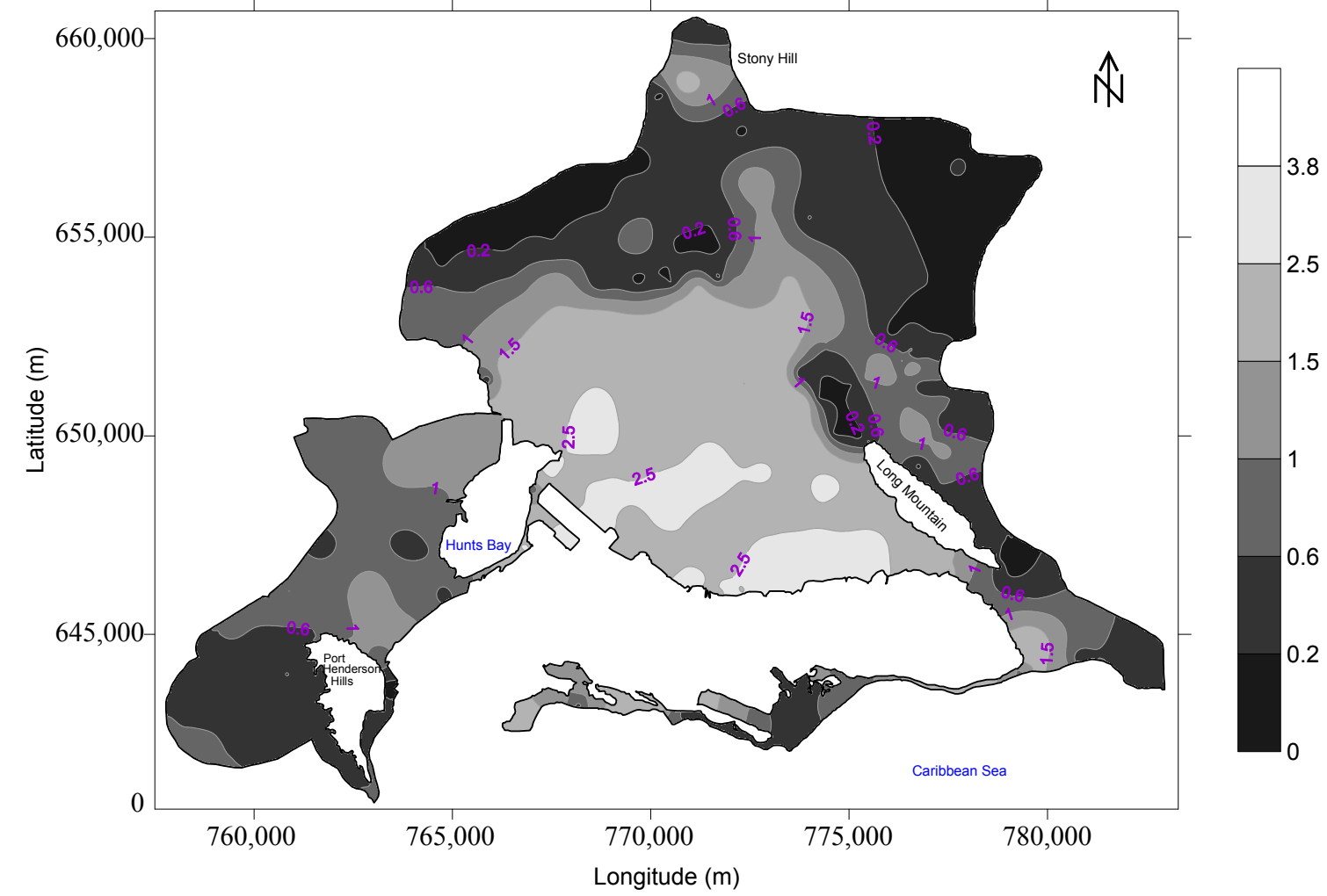

Fig. 11 Isoperiod map for Kingston Metropolitan Area, the units for the period are in s. 


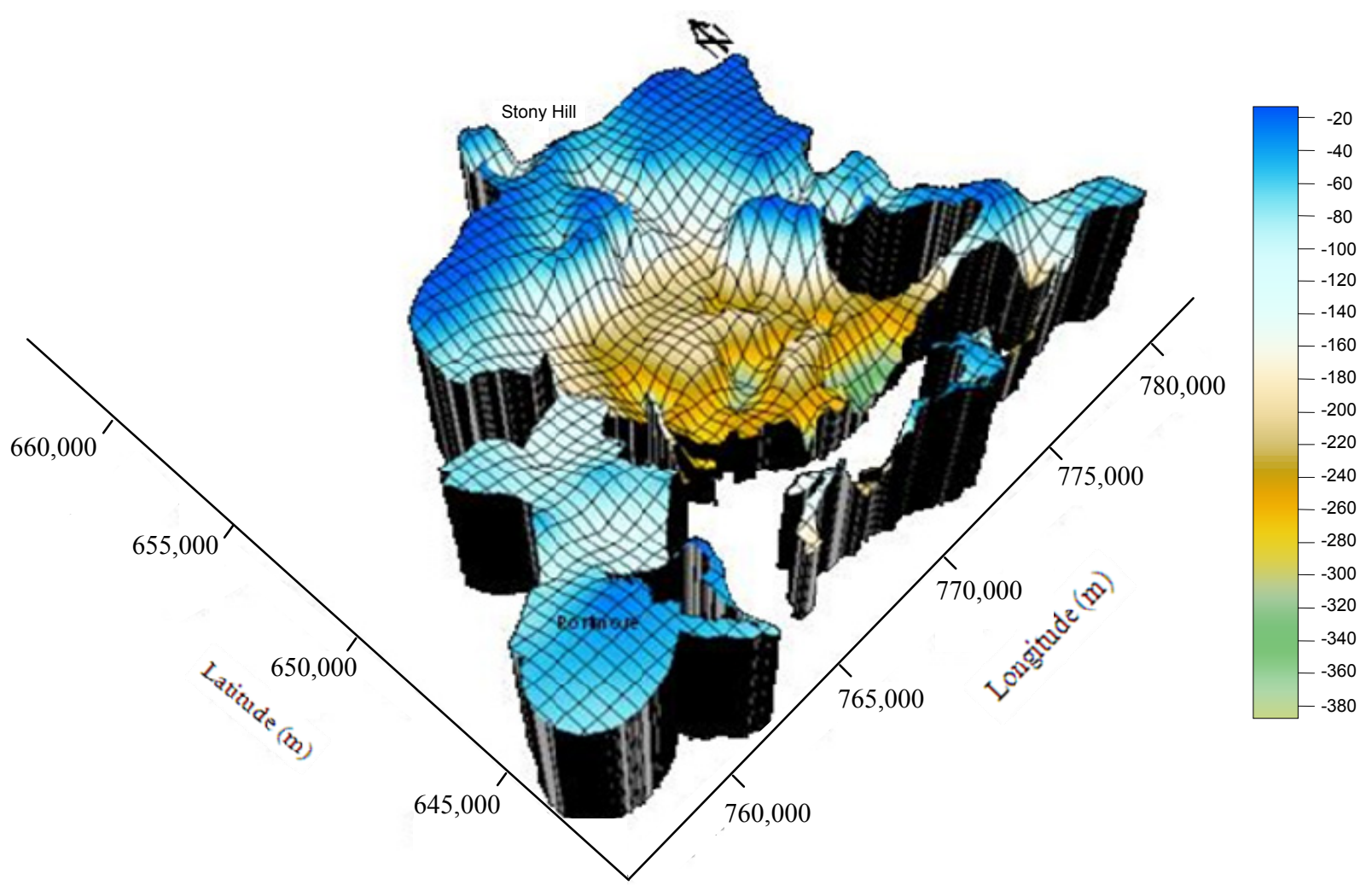

Fig. 12 A 3-D sediments depth model for Kingston Metropolitan Area based on the period of the soil deposits and an average shear wave velocity of $410 \mathrm{~m} / \mathrm{s}$, the units of depth are in $\mathrm{m}$.

McNamara et al. [26], $v_{S}=3.8 \mathrm{~km} / \mathrm{s}$ at the correspondent distance $R$ from the earthquake and compare with both, the $\mathrm{H} / \mathrm{V}$ ratio derived from microtremors and the strong motion records; although originally proposed to analyze microtremor data, Lermo and Chávez-García [27] applied the $H / V$ ratio technique to earthquake ground motions recorded on soft sediments in Mexico City, and obtained a good coincidence with microtremor-based predominant periods.

Figs. 13 and 14 illustrate the amplification spectra resulting from the application of this procedure for an earthquake event on 2011/05/06 09:29:22 UTC and Mw 4.7 with an epicenter north-east of Kingston $(18.087 \mathrm{~N}, 76.652 \mathrm{~W})$ and a shallow depth of $5 \mathrm{~km}$. For the station at the Toll Office in Portmore (SMS1), it is clear that a very good match is observed for the predominant peak for $\mathrm{H} / \mathrm{V}$ of microtremors at $2.0 \mathrm{~s}$ and the amplification factors derived from the $\omega^{2}$ model. Similar characteristics are observed for the strong motion at the station SMS2 on Portmore Bridge for the same earthquake at the period of $2.5 \mathrm{~s}$, the sharp peak at $0.65 \mathrm{~s}$ derived from the $\omega^{2}$ model and the H/V could be attributed to the structural response being the instrument located on one of the pillar footings of the bridge. The authors performed the microtermor measurement about $25 \mathrm{~m}$ away from this station due to the immediate inaccessibility, being the footing of the bridge surrounded by water. For both stations, the H/V obtained by the earthquake recording present peaks in longer periods, but not so well defined as the ones obtained by microtermor recordings and the $\omega^{2}$ model. The authors attribute these differences to the fact that the vertical component comprised of body waves undergoes no amplification for microtremors as stated by Nakamura [3], while significant amplification can take place in the vertical component during earthquakes with earthquake epicenters located near the station.

Konno and Ohmachi [10] suggested a simple formula 

at Kingston Metropolitan Area, Jamaica

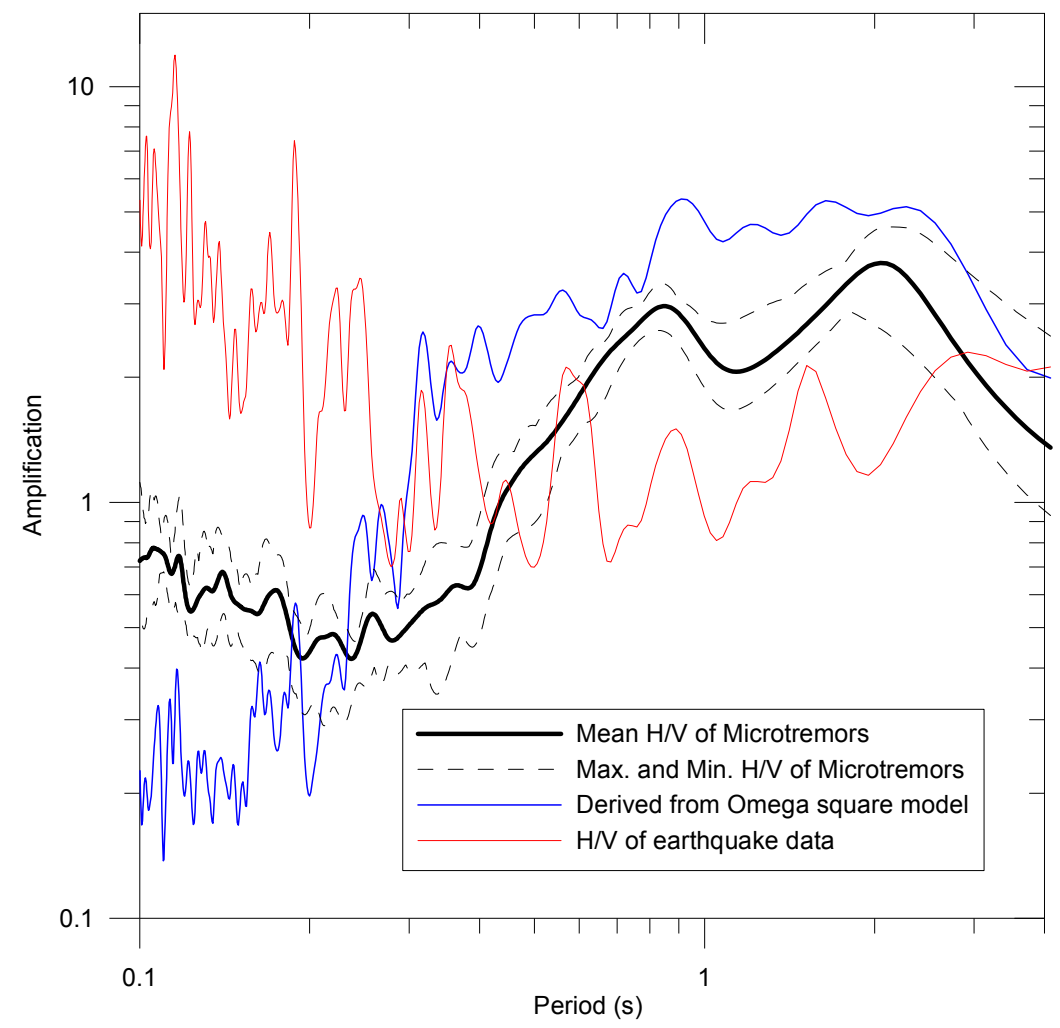

Fig. 13 Comparison of transfer functions of microtremors and strong motion data for the Toll Office at Portmore (SMS1 in Fig. 1).

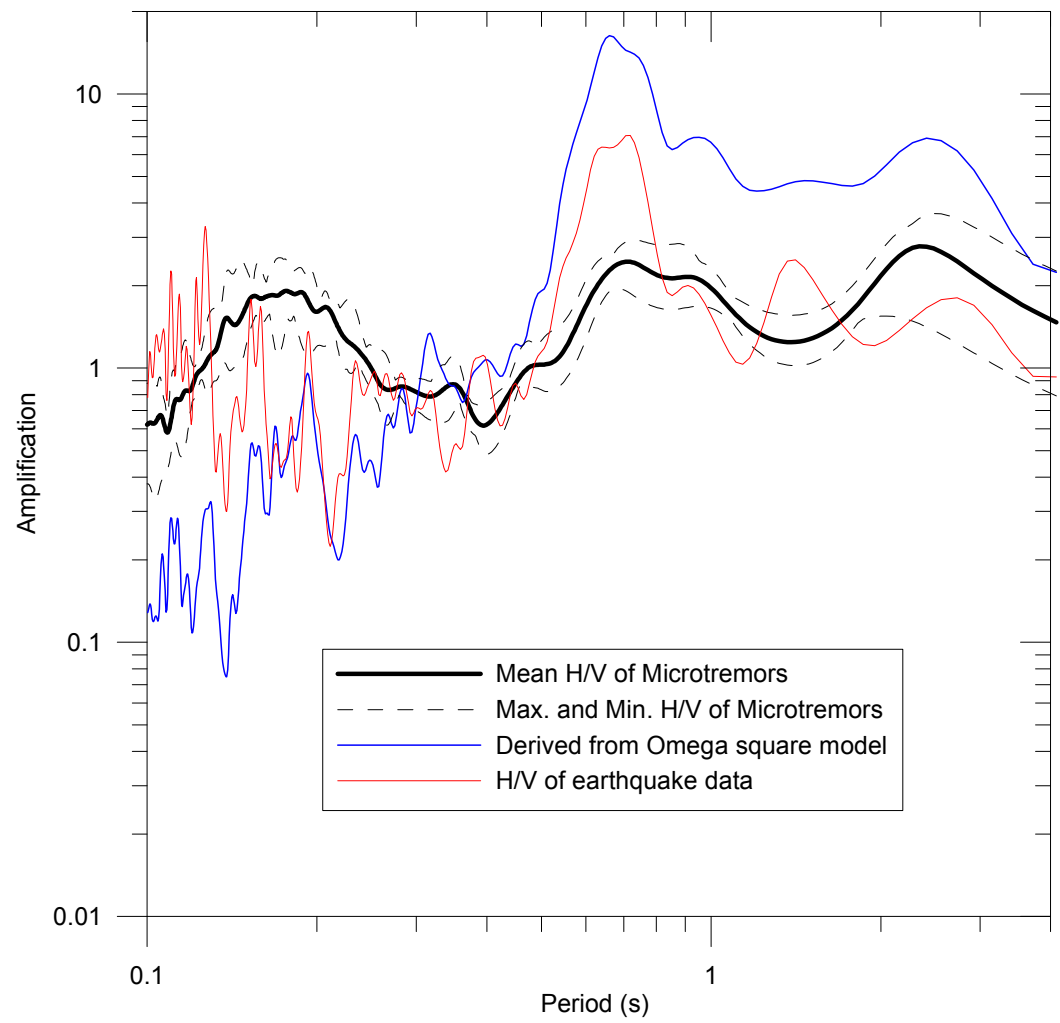

Fig. 14 Comparison of transfer functions of microtremors and strong motion data for the Bridge at Portmore (SMS2 in Fig. 1). 


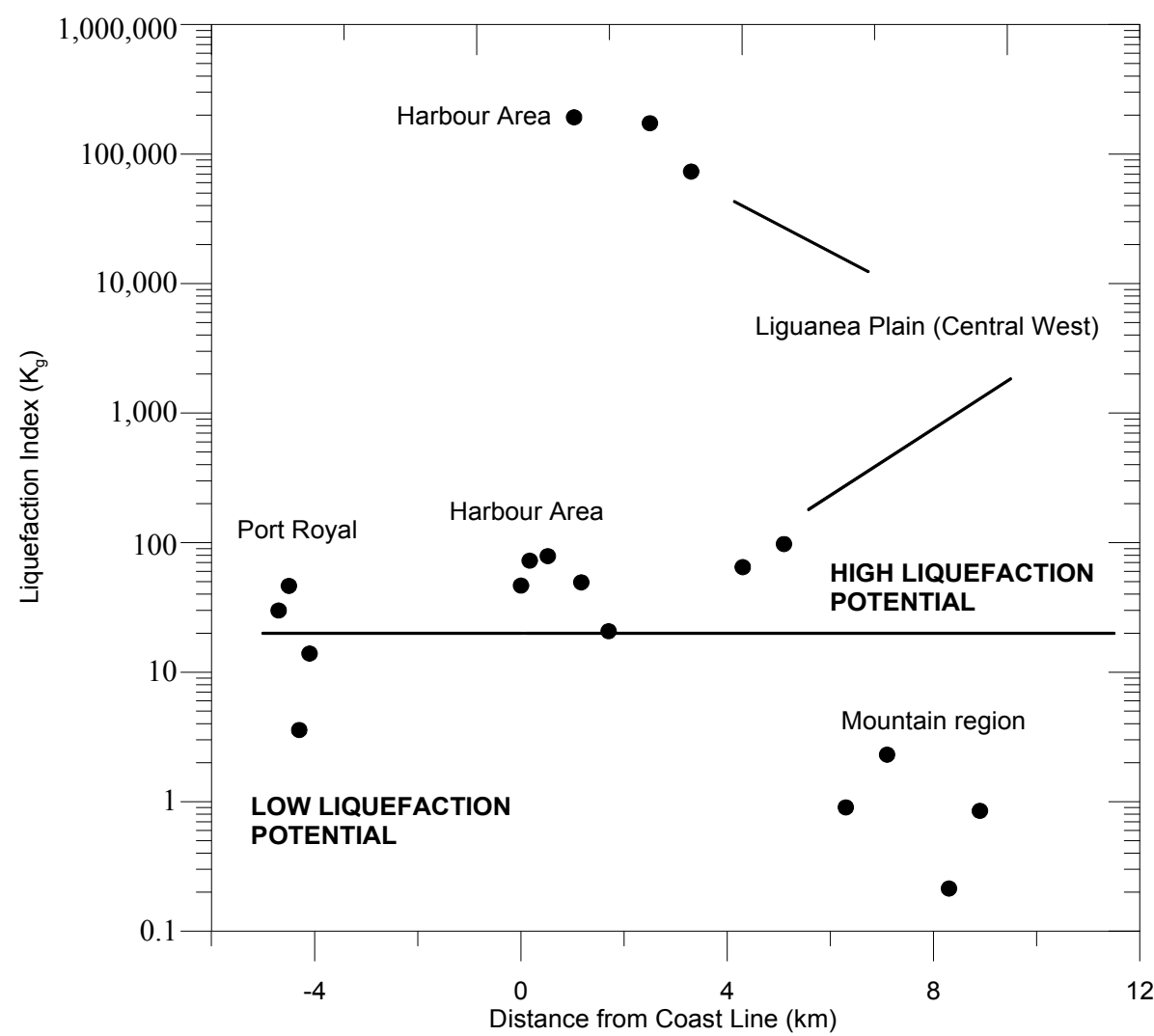

(a)
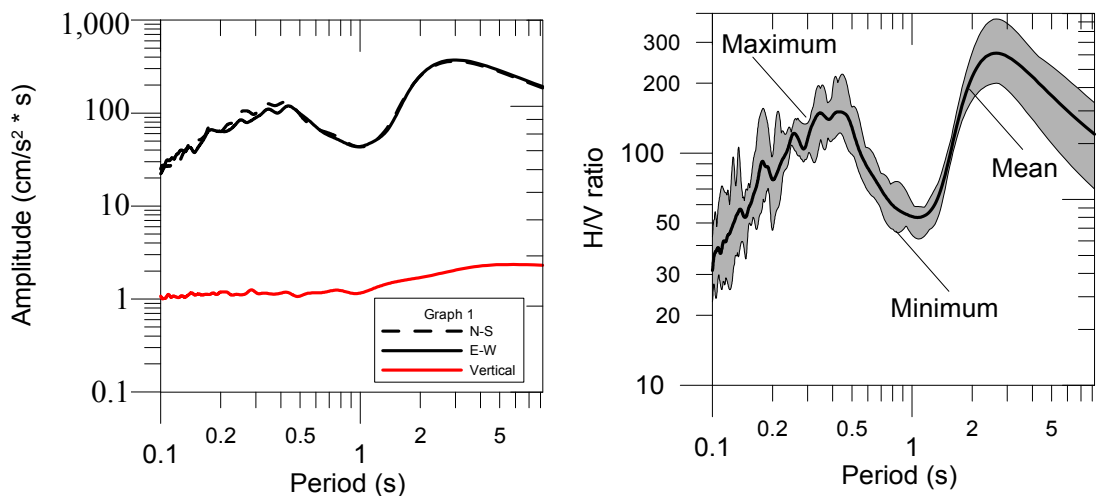

(b)

Fig. 15 The harbour area, Port Royal and some areas at the Liguanea Plain have a high liquefaction potential: (a) Liquefaction index $K_{g}$ based on microtremor measurements depicted in Figs. 5 and 6 and the polygon depicted in Fig. 1; (b) absolute Fourier spectrum and anomalous $\mathrm{H} / \mathrm{V}$ spectral ratio in the harbor area.

for the amplification factor $A_{S}$ using $\mathrm{H} / \mathrm{V}$ ratio of microtremors, as follows:

$$
A_{S} \approx R_{M B}
$$

where, $R_{M B}$ denotes the ratio at the peak. In this case, we can attribute an amplification factor of 4 at $2.0 \mathrm{~s}$ for SMS1, of 3.0 at $2.5 \mathrm{~s}$ for SMS2.

\section{Preliminary Assessment of Liquefaction Potential}

Nakamura [13] proposed a simple technique to investigate the liquefaction potential based on microtremor measurements, namely the vulnerability index $K_{g}$ for the surface ground, as follows: 


$$
K_{g}=\frac{A_{g}^{2}}{F_{g}}
$$

where, $A_{g}$ is the amplification factor referenced to the engineering bedrock and $F_{g}$ is the predominant frequency of the soil profile (the inverse of the fundamental period), both values can be taken from the horizontal to vertical spectral ratio $(\mathrm{H} / \mathrm{V})$ of microtremors, $A_{g}$ is considered to be the $\mathrm{H} / \mathrm{V}$ ratio at the predominant frequency [10]. Values of $K_{g}$ greater than 20 are considered likely to liquefy.

The authors applied this method to the cross section in Fig. 1 and $\mathrm{H} / \mathrm{V}$ ratios presented in Fig. 6. The results show that the harbour area, Port Royal and some areas at the Liguanea Plain have a high liquefaction potential (Fig. 15). It is worth mentioning that anomalous $\mathrm{H} / \mathrm{V}$ ratios above 100 for long period components between 2-2.5 s are observed in the Liguanea and the harbor area (Fig. 6, H/V ratios number 8,7 and 11) due to the very low amplitude and flat vertical absolute Fourier spectra at these sites indicating a small contribution of Rayleigh waves in the micromotion, however, the authors observed the same fundamental periods in the $\mathrm{H} / \mathrm{V}$ ratio at other sites where significant vertical amplitudes appear. Despite the difference in the energy in vertical component of motion at different sites, this phenomenon confirms that the quasi-transfer function provides the fundamental period due to the multiple refraction of $\mathrm{SH}$ waves in the surface ground layers regardless of the influence of the degree of Rayleigh waves. These characteristics were observed also at some points in the waterfront area. As a further evidence, Nakamura [14] suggested that in the case of a low effect of Rayleigh waves, it is possible to estimate both the fundamental periods and the second mode caused by the multiply reflections of S-waves. These characteristics were observed also at some points in the waterfront area.

Performing continuous measurements at these sites during one or two weeks will help to clarify the distinction of long period microtremors or microseisms due to ocean waves excitation and short period microtermos (Kanai's microtremors) due to human activity, traffic, machinery, etc. [28].

The new Probabilistic Seismic Hazard Assessment for Jamaica (see the article in the previous issues) suggests a Peak Ground Acceleration for 475 and 2,475 years return period KMA of $0.25 \mathrm{~g}$ and $0.45 \mathrm{~g}$ respectively at rock site conditions in KMA; the saturated sediments on those areas can be classified as sand/silty where the water table is located at the surface. Liquefaction phenomena were observed during the earthquake of 1907 at Port Royal (Fig. 16).

\section{Microtremor Measurments on Buildings}

We measured microtremors in the roof and in the basement of four reinforced concrete buildings in KMA in order to investigate the translational period of vibration. The buildings for which we measured the microtremors were: Ministry of Agriculture, Petroleum Corporation of Jamaica, Ministry of Health and UDC (urban development corporation) Office Centre Building.

In order to eliminate the influence of the soil on the roof measurements on the buildings, we divided them by the micromotion recorded on the basement. Fig. 17 depicts the amplification functions of the buildings showing clear predominant periods of vibration in the transversal and longitudinal directions (Table 1). As a

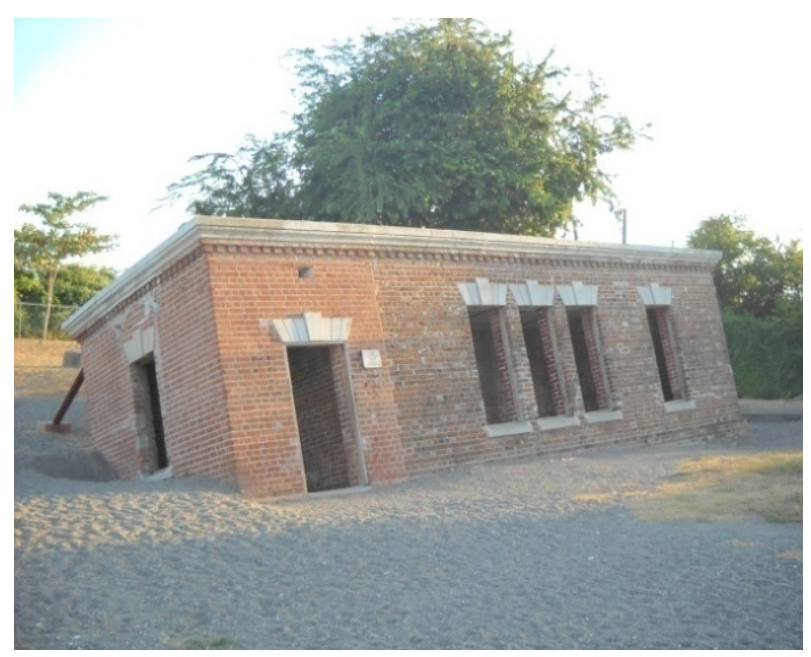

Fig. 16 Liquefaction phenomena is still evident in the "Giddy House", an ammunition store at Port Royal during the 1907 earthquake. 

at Kingston Metropolitan Area, Jamaica
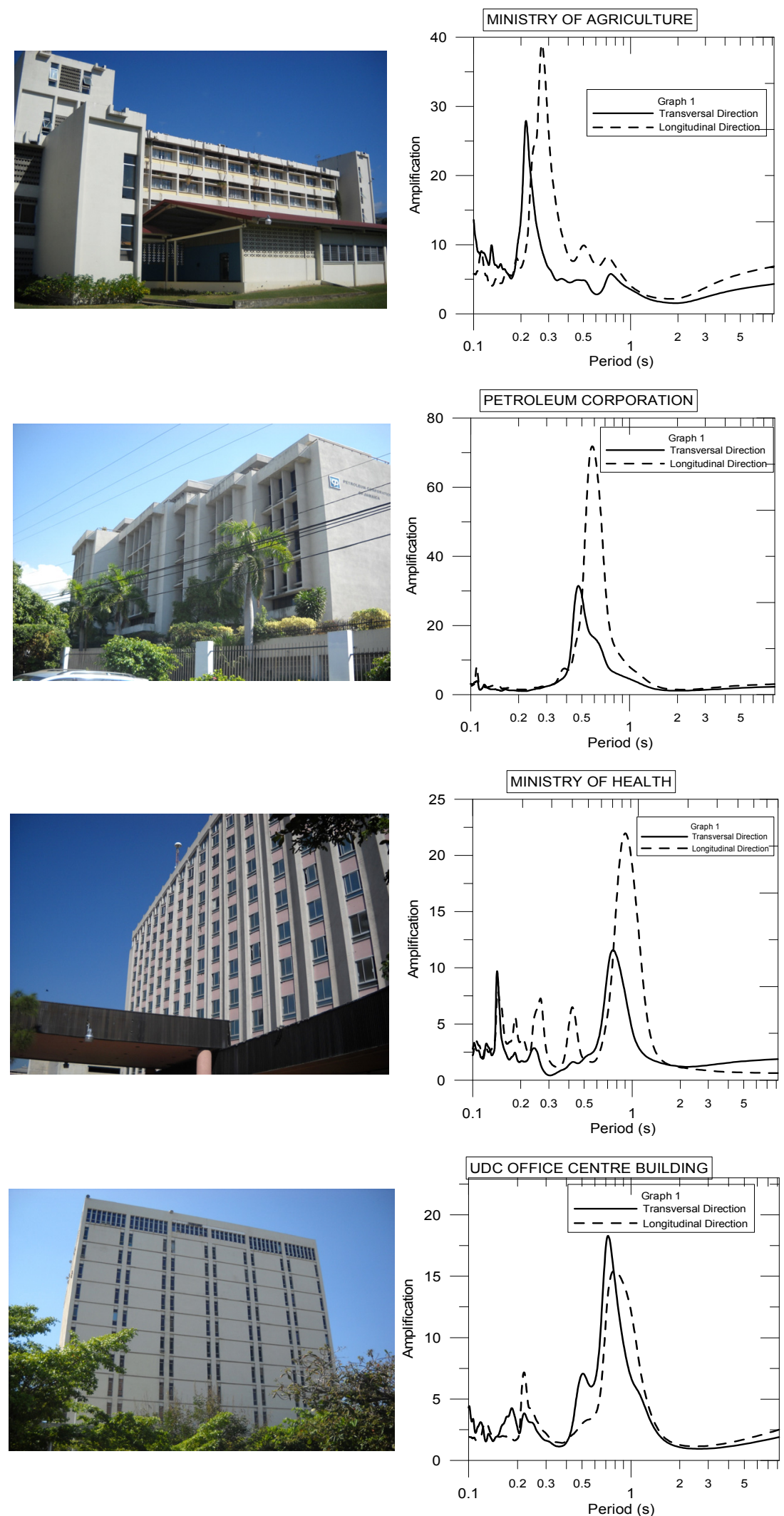

Fig. 17 Transfer function for reinforced concrete buildings based on microtremor measurements at the top and the bottom of the buildings. 
Table 1 Fundamental period of vibration and damping as percentage of the critical for buildings in Kingston Metropolitan Area for transversal and longitudinal directions.

\begin{tabular}{lll}
\hline Name of the building & \multicolumn{2}{c}{ Fundamental period (s) } \\
\cline { 2 - 3 } & Transversal & Longitudinal \\
\hline Ministry of Agriculture & 0.22 & 0.27 \\
Petroleum Corporation of & 0.48 & 0.58 \\
Jamaica & 0.76 & 0.90 \\
Ministry of Health & 0.73 & 0.79 \\
UDC Office Centre Building &
\end{tabular}

preliminary observation, we note that the amplification factors between the transversal and the longitudinal directions differ twice and sometimes three times, the lowest ones being always in the transversal directions for which we observe the shortest fundamental period of vibration, in other words, the microtremor measurements reveal that the longitudinal direction of the buildings is more flexible than the transversal direction. An appropriate seismic coefficient might have been taken into account during the phase structural design in accordance with the architectural building configuration and the stiffness/flexibility observed in both directions.

\section{Conclusions}

At the Kingston Metropolitan Area, intensities of MM VI or greater have been reported at a rate of 20 times per century, constituting the largest rate amongst all Jamaican cities [29]. The authors clearly attribute this fact to effects of the surface geology on the earthquake ground motion in the city yielding average depth of the sediments ranging from 200-300 m and periods of about 2.0-3.0 s in the Liguanea basin.

Despite the fact that the predominant period of vibration based on the $\mathrm{H} / \mathrm{V}$ of microtremor measurements coincide well with available geological information, a more precise "level of amplification" during future earthquakes at KMA is still a question to solve. The authors have elucidated amplification factors of about 3-4 for periods ranging 1.0-2.0 s employing a very limited amount of earthquake ground motion and microtremor data, but such few samples lead to inconclusive statements for the whole city, even more for short period components of ground motion (0.1-1.0 s). In this regard, fundamental future work in the area to perform microtremors array observation is recommended in order to retrieve the shear wave velocity profile information reaching the bedrock based on conventional methods as the SPAC (spectral auto correlation). Such arrays might be done in different parts of the city in order to give proper amplification factors that are dependent of frequency, and to scale up the elastic design spectra developed in the seismic hazard assessment for rock site conditions presented in another article of the previous issues. The first microzonation maps for KMA must be done for both, the level of amplification with its correspondent seismic loads and the liquefaction potential, which the authors have demonstrated, represents a high hazard especially in the Kingston harbour areas and Port Royal. Kingston ranks as the 7th largest natural harbour in the world and has a large concentration of infrastructure through the KMA like oil refineries, power generation plants and high rise buildings. The seismic hazard paper presented in this previous issues clearly demonstrated that a moderate size earthquake can produce long term economic impact in the country due to the substantial level of shaking, and the amplification phenomena caused by the presence of unconsolidated and saturated soils in the region.

The source of the microtremors can be elucidated if continuous measurements are performed simultaneously on rock and soil $[28,30]$ and compare their amplitude with those of ocean wave heights or changes in atmospheric pressure at the harbour. Their survey indicates that long period microseisms are present at rock site conditions observing a peak in the long period components (above $4.0 \mathrm{~s}$ ) in the "absolute" Fourier spectrum that clearly does not correspond to the presence of sediments at these sites (i.e., Figs. 8a and 10d). Then the long period microtremors (microseisms) and short period microtremors (Kanai's 
microtremors) must be distinguished in future research with continuous measurements at strategic points in the city at rock site and deep soil conditions.

The deployment of a dense earthquake strong motion network in the KMA is a must in order to validate the results from the microtremors survey together with systematic boreholes data that can validate the microtremors array observation cited above and the amplification factors that would arise with the earthquake data. A future line of research in the region is the acquisition of the dynamic properties of medium and high rise buildings employing microtremors, namely the fundamental translational and rotational period of vibration and the damping ratio, especially in zones where the resonant phenomena is likely to occur.

\section{Acknowledgments}

Maps have been prepared using ESRI Arc Map 10.1 (Arc View) Geographic Information System and SURFER Golden Software 8.

This study has been funded by the World Bank as a part of the Risk Atlas Project for the Caribbean under the supervision of the DRRC (Disaster Risk Reduction Centre) at the University of the West Indies, Mona, Jamaica.

The authors thank Paul Williams, Karleen Black, Raymond Stewart, Stephanie Grizzle, Laurel Choy (Earthquake Unit, Jamaica) and Omari Graham (SRC/UWI, Trinidad) for assisting the authors in the microtremors survey at Kingston Metropolitan Area. The authors also thank the following institutions that permitted them to make measurements at their facilities/buildings:

(1) Kingston Container Terminal;

(2) The Port Authority of Jamaica;

(3) The Airport Authorities of Jamaica;

(4) Jamaica Defense Force;

(5) Urban Development Corporation;

(6) Ministry of Health and the Environment;

(7) Ministry of Agriculture;
(8) Petroleum Corporation of Jamaica.

\section{References}

[1] W. Salazar, V. Sardina, J. Cortina, A hybrid inversion technique for the evaluation of source, path and site effects employing S-wave spectra for subduction and upper-crustal earthquakes in El Salvador, Bull. Seismol. Soc. Am. 97 (2007) 208-221.

[2] W. Salazar, K. Seo, Earthquake disasters of January 13th and February 13th 2001, El Salvador, Seismological Research Letters 74 (4) (2003) 420-439.

[3] Y. Nakamura, A method for dynamic characteristics estimation of subsurface using microtremor on the ground surface, Quaterly Report of Railway Technical Research Institute 30 (1) (1989) 25-33.

[4] R. Ahmad, E. Robinson, Geological evolution of the Liguanea Plain-The landslide connection, in: Proceedings of the First Conference, Faculty of Natural Sciences, The University of the West Indies, Mona, May 1994, pp. 22-23.

[5] National Disaster Research, Inc., The Earthquake Unit, UWI, Mines and Geology Division, Jamaica, Kingston Metropolitan Area: Seismic Hazard Assessment Final report, U.S. Agency For International Development/Organization of American States, Caribbean Disaster Mitigation Project, Kingston Multi-Hazard Assessment, 1999, p. 82.

[6] M. Wiggins-Grandinson, T. Kebeasy, E. Husebye, Enhanced earthquake risk of Kingston due to wave field excitation in the Liguanea Basin, Jamaica, Caribbean Journal of Earth Science 37 (2003) 21-32.

[7] M.D. Wiggins-Grandison, Jamaican seismology and seismic hazard parameters, in: Jamaica Building Code Conference, Jamaica Pegasus Hotel, Kingston, Sep. 27-28, 2007.

[8] M. Nogoshi, T. Igarashi, On the amplitude characteristics of Microtremors (Part I), Jour. Seis. Soc. Jap. 23 (1970) 281-303.

[9] V. Rodríguez, S. Midorikawa, Applicability of the H/V spectral ratio of microtremors in assessing site effects on seismic motion, Earthquake Engineering and Structural Dynamics 31 (2002) 261-279.

[10] K. Konno, T. Ohmachi, Ground-motion characteristics estimated from spectral ratio between horizontal and vertical components of microtremors, Bull. Seismol. Soc. Am. 88 (1998) 228-241.

[11] R. Borchedt, Effects of local geology on ground motion in San Francisco Bay, Bull. Seismol. Soc. Am. 60 (1970) 29-61.

[12] W. Aspinall, J. Shepherd, Modelling earthquake response of the Liguanea-St. Catherine Plain of Jamaica in: 8th 
Caribbean Geological Conference, Curacao, 1977.

[13] Y. Nakamura, Seismic vulnerability indices for ground and structures using microtremors, in: World Conference on Railway Research, Florence, 1997.

[14] Y. Nakamura, On the H/V spectrum, in: The 14th World Conference on Earthquake Engineering, Beijing, China, Oct. 12-17, 2008.

[15] J. Turnosvsk, J. Shepherd, Microzoning for Earthquake Effects in Kingston, Report No. 2, Mines and Geology Division, Ministry of Mining and Natural Resources, Seismic Research Unit, The University of the West Indies, 1976.

[16] W. Salazar, K. Seo, Spectral and amplification characteristics in San Salvador City (El Salvador) for upper-crustal and subduction earthquakes, in: 11th Japan Earthquake Engineering Symposium, Japan, 2002, pp. 329-334.

[17] J. Wald, T. Allen, Topographic slope as a proxy for seismic site conditions and amplification, Bull. Seismol. Soc. Am. 97 (5) (2007) 1379-1395.

[18] J. Brune, Tectonic stress and spectra of seismic shear waves from earthquakes, J. Geophys. Res. 75 (1970) 4997-5009.

[19] L. Reiter, Earthquake hazard analysis, issues and insights, Surveys in Geophysics 13 (3) (1992) 297-298.

[20] G. Atkinson, Earthquake source spectra in eastern north America, Bull. Seismol. Soc. Am. 83 (6) (1983) 1778-1798.

[21] N.A. Haskell, Total energy and energy spectral density of elastic wave radiation from propagating faults, Bull. Seismol. Soc. Am. 54 (1964) 1811-1841.

[22] R. McGuire, T. Hanks, RMS accelerations and spectral amplitudes of strong ground motion during the San Fernando, California Earthquake, Bull. Seismol. Soc. Am. 70 (5) (1980) 1907-1919.

[23] D. Boore, Stochastic simulation of high-frequency ground motions based on seismological models of the radiated spectra, Bull. Seismol. Soc. Am. 73 (6) (1983) 1865-1894.

[24] G. Atkinson, D. Boore, Evaluation of models for earthquake source spectra in eastern north America, Bull. Seismol. Soc. Am. 88 (4) (1998) 917-934.

[25] T. Hanks, H. Kanamori, A moment magnitude scale, J. Geophys. Res. 84 (1979) 2348-2350.

[26] D. McNamara, M. Meremonte, J.Z. Maharrey, S.L. Mildore, J.R. Altidore, D. Anglade, et al., Frequency-dependent seismic attenuation within the Hispaniola Island Region of the Caribbean Sea, Bull. Seismol. Soc. Am. 102 (2012) 773-782.

[27] J. Lermo, J. Chávez-García, Are microtremors useful in site response evaluation?, Bull. Seismol. Soc. Am. 84 (1994) 1350-1364.

[28] K. Seo, On the applicability of microtremors to engineering purposes: Preliminary report of the joint ESG research on microtremors after the 1993 Kushiro-oki (Hokkaido, Japan) Earthquake, in: 10th European Conference on Earthquake Engineering, Rotterdam, 1995.

[29] J. Shepard, W. Aspinall, Seismicity and seismic intensities in Jamaica, West Indies: A problem in risk assessment, Earthquake Engineering and Structural Dynamics 8 (1980) 315-335.

[30] K. Seo, JICA Research and Development Program on Earthquake Disaster Prevention, The Japan Building Disaster Prevention Association, JICA (Japan International Cooperation Agency), 1997. 